\title{
DIEZ ESPECIES NUEVAS DE GUAREA (MELIACEAE) DE NICARAGUA, COSTA RICA Y PANAMÁ
}

\author{
AlexÁNDER RodríGUEZ \\ Instituto Nacional de Biodiversidad (INBio), apdo. 22-3100, Santo Domingo, Heredia, Costa Rica, \\ arodrig@inbio.ac.cr
}

\begin{abstract}
Ten new species of Guarea from Nicaragua, Costa Rica and Panama are described and illustrated, and their relationships to other species of the genus are discussed.
\end{abstract}

Resumen. Se describen e ilustran 10 especies nuevas de Guarea de Nicaragua, Costa Rica y Panamá; además, se discuten sus afinidades con otras especies del género.

Palabras clave / Key words: Meliaceae, Guarea, Costa Rica, Nicaragua, Panamá.

El nombre Guarea fue establecido por Linneo en 1753 como Guara; él mismo modificó la ortografía en 1771 a Guarea (Coronado 2003). Entre las primeras revisiones importantes del género encontramos la de Casimir De Candolle (1878), quien en una monografía completa para la familia Meliaceae reconoció dos secciones, EuGuarea (actualmente Guarea), con 67 especies, y la sección Ruagea, con tres especies, actualmente reconocida como un género distinto (Coronado 2003). En la última revisión completa del género se reconocen 35 especies (Pennington et al. 1981). Sin embargo, una investigación reciente que toma como base este último estudio (Coronado 2003) evaluó Guarea glabra Vahl entre México y Panamá y reconoció que este taxon es un complejo que incluye 15 especies distintas; de éstas, Pennington et al. (1981) consideran nueve como sinónimos de G. glabra y cinco especies son inéditas y diferentes a las descritas aquí. En su estudio, Coronado (2003) reconoce las siguientes especies: G. arcuata Coronado -ined, G. bullata Radlk., G. chiricana Standl., G. excelsa Kunth, G. gentryi Coronado -ined, G. glabra Vahl, G. glabrescens (Hook. \& Arn.) Blake, G. kegelii Turcz., G. luxii C. DC., G. mexicana Coronado -ined, G. microcarpa C. DC., G. petenensis Coronado ined, G. tonduzii C. DC., G. tuerckheimii C. DC. y G. zarceronensis Coronado -ined.

Algunas floras locales han sido aportes regionales importantes en la revisión de este género; tal es el caso de Flora de Guatemala (Standley \& Steyermark 1946), Flora de Panamá (Smith 1965) y Flora de Nicaragua (Pennington \& Styles 2001). Según Pennington \& Styles (1975), Guarea pertenece a la tribu Guareeae, de la subfamilia Melioideae. El género se caracteriza por estar constituido por árboles o arbustos con hojas alternas, compuestas, generalmente pinnadas y en la mayoría de los casos con una yema terminal de crecimiento intermitente; son plantas dioicas, con flores unisexuales por aborto, aunque pareciendo perfectas, con un cáliz cupuliforme, pétalos libres, en la mayoría de los casos valvados, estambres con filamentos completamente unidos y formando un tubo cilíndrico, un ginóforo corto y un nectario anular en la base del ovario, este último con 2 a 13 lóculos, lóculos generalmente con 1 ó 2 óvulos, estigma discoide, frutos capsulares, con 2 a 10 (-14) valvas, dehiscentes, en la mayoría de los casos con 1 ó 2 semillas por lóculo, rodeadas por una sarcotesta carnosa, roja o anaranjada.

Las exploraciones botánicas de Costa Rica han aportado en los últimos años nuevos y numerosos especímenes de herbario. Hasta 1981, año en que Pennington et al. publicaron la última revisión de la familia Meliaceae en el Neotrópico, el Herbario Nacional de Costa Rica (CR) contaba con alrededor de 168 especímenes de Guarea (Museo Nacional de Costa Rica 2006). Actualmente, este herbario posee 534 especímenes de este género, mientras que paralelamente y a partir de 1989 el herbario del Instituto Nacional de Biodiversidad (INB) ha acumulado 433 ejemplares de Guarea (Atta-INBio 2006). Este significativo aumento en el número de especímenes ha permitido un mejor estudio y diagnóstico de las especies de este género; por tanto, no sorprende que se hayan registrado nuevos taxa.

Según Pennington \& Styles (2001), cerca de 40 especies de Guarea habitan en América tropical y cinco en África tropical. Con el aporte de Coronado (2003) y las especies descritas aquí, los trópicos americanos 
registran alrededor de 65 especies de Guarea. Las siguientes especies nuevas son parte de los resultados obtenidos en la preparación del tratamiento de Guarea para el Manual de Plantas de Costa Rica.

\section{Guarea adenophylla Al Rodr., sp. nova}

Species haec nova per sequentes characteres distinguenda est: Folioli subtus copiose rubescentiglandulosi, ovarii loculi uniovulati, ovarium sparse breveque pilosum, fructi glóbulosi, semen unum per loculum.

TIPO: COSTA RICA. Puntarenas; Puntarenas, Monteverde, Pacific slope, lower montane wet forest, upper community, Cambell farm, $1500 \mathrm{~m}, 10^{\circ} 18^{\prime} \mathrm{N}$, 84² 48'W, 30 jul 1991 (fl), W. Haber 10791 (Holotipo: INB, isotipo: CR). Fig. 1.

Árbol entre 4 y $20 \mathrm{~m}$ de altura; tallitos esparcida a densamente pilósulos, al menos en ramitas terminales, con o sin lenticelas esparcidas. Hojas pinnadas, con una yema terminal de crecimiento intermitente; pecíolos 1.5-7 cm de largo, puberulentos a glabrescentes con la edad, subteretes, lado adaxial levemente aplanado y con bordes apenas agudos; raquis $2-31 \mathrm{~cm}$ de largo, puberulento a glabrescente con la edad, largo entre foliolos 2-9 cm, subcuadrado y canaliculado en el lado adaxial; foliolos 1-8 pares, opuestos, peciólulos 0.3-1 cm de largo y 1.5-4 mm de ancho; lámina 3-25 $\mathrm{cm}$ de largo y 2-9 cm de ancho, elíptica, oblongoelíptica a oblongo-obovada, verde-grisácea a grisrojiza al secar, adaxial y abaxialmente concolora, haz sin papilas, si presentes entonces restringidas al nervio principal, envés esparcidamente pubescente, con abundantes glándulas rojizas, base cuneada, ápice agudo o cuspidado, nervadura eucamptódroma, 6-14 pares de venas secundarias. Inflorescencias axilares, solitarias o fasciculadas, paniculadas, $2-16 \mathrm{~cm}$ de largo, ramas laterales hasta $4 \mathrm{~cm}$ de largo, multifloras, erectas, pedúnculo $0.3-2 \mathrm{~cm}$ de largo, en ocasiones indefinido. Flores con pedicelos entre 1 y $5 \mathrm{~mm}$ de largo, articulados, generalmente con 1 ó 2 bracteolas entre $0.3-0.75 \mathrm{~mm}$ de largo. Flores estaminadas con cáliz 1-2.5 $\mathrm{mm}$ de largo, pateliforme a ciatiforme, esparcidamente estrigoso, lóbulos 4 , incisos 1/4-3/4 del tamaño del cáliz; pétalos 4, 7-11 mm de largo y 2.5-3.5 mm de ancho, crema a verde-crema, ápice agudo, lado externo esparcidamente pubescente hacia la parte distal, interno papilado; tubo estaminal 5-7 $\mathrm{mm}$ de largo y 2-2.5 mm de ancho, ápice crenulado, lado externo papilado; anteras 8, 0.7-1 mm de largo y
0.6-0.8 $\mathrm{mm}$ de ancho; ginóforo 1-1.5 mm de largo y $1.25-1.5 \mathrm{~mm}$ de ancho, glabro, nectario $0.3-0.5 \mathrm{~mm}$ de largo, conspicuo; ovario $1-1.3 \mathrm{~mm}$ de largo y $0.7-1 \mathrm{~mm}$ de ancho, esparcida a densamente pubescente; pistilo igual o sobrepasando levemente el tubo estaminal, estilo 2.5-3 $\mathrm{mm}$ de largo, esparcida a densamente pubescente en la base, glabro en las $3 / 4$ partes distales, estigma $0.3-0.5 \mathrm{~mm}$ de largo y $1-1.25 \mathrm{~mm}$ de diámetro. Flores pistiladas con cáliz 1-1.5 mm de largo, pateliforme, esparcidamente pubescente, lóbulos 4-5, apenas definidos o hasta 1/4-3/4 del tamaño del cáliz; pétalos no observados; tubo estaminal $9-10 \mathrm{~mm}$ de largo y 3-3.5 mm de ancho, ápice crenulado, lado externo glabro; anteroides $8,0.8-1 \mathrm{~mm}$ de largo y 0.25-0.4 $\mathrm{mm}$ de ancho; ginóforo $0.75-1 \mathrm{~mm}$ de largo y $1.75-2 \mathrm{~mm}$ de ancho, glabro, nectario $0.5-0.75 \mathrm{~mm}$ de largo, conspicuo; ovario tetra o pentalocular, 3-3.5 $\mathrm{mm}$ de largo y 2-2.5 $\mathrm{mm}$ de ancho, con un óvulo por lóculo, esparcidamente pubescente; pistilo subigual al tubo estaminal, estilo 2-4 mm de largo, esparcidamente pubescente hacia la base, grabrescente en 3/4 partes distales, estigma $c a .0 .25 \mathrm{~mm}$ de largo y $0.75 \mathrm{~mm}$ de diámetro (descripción de flores pistiladas basada en vestigios florales presentes en frutos inmaduros). Frutos $1-2.5 \mathrm{~cm}$ de largo y $1-2.5 \mathrm{~cm}$ de ancho, globulosos, no acostillados, esparcidamente lenticelados, rojizos al madurar, esparcidamente pubescentes a glabrescentes con la edad, tetra o pentaloculares, ginóforo 1-1.5 mm de largo, base obtusa, ápice obtuso a subtruncado, pericarpo 1-2 $\mathrm{mm}$ de grosor; semillas 1 por lóculo, 1$1.2 \mathrm{~cm}$ de largo, subrodeadas por la sarcotesta.

Distribución. Costa Rica y Panamá. Se conoce en bosques pluviales, en Costa Rica en ambas vertientes de la Cordillera de Guanacaste, de Tilarán y Central; en Panamá en Bocas del Toro-Chiriquí, entre 1580 y $1650 \mathrm{~m}$ de elevación.

Fenología. Flores en enero, marzo, julio y octubre; frutos entre enero y mayo, además en julio, agosto y diciembre.

G. adenophylla se reconoce por la combinación de los siguientes caracteres morfológicos: envés de los foliolos con abundantes glándulas rojizas (en ocasiones escasas en hojas viejas), flores con ovario tetra o pentalocular, esparcida y cortamente piloso, lóculos uniovulados, lado externo de los pétalos con pubescencia esparcida hacia la parte distal (al menos en flores pistiladas) y frutos globulosos, con una semilla por lóculo; además, se caracteriza por hábito arborescente, partes vegetativas esparcida a densamente pubescentes (al menos en ramitas terminales), hojas con hasta ocho 
pares de foliolos e inflorescencias paniculadas.

Esta especie se podría relacionar con la ampliamente distribuida G. glabra Vahl al considerar los conceptos taxonómicos de Pennington (1981), que incluyen ovario tetra o pentalocular, pubescente, con un óvulo por lóculo, pétalos esparcidamente pubescentes, nunca alcanzando más de $12 \mathrm{~mm}$ de largo, frutos globulosos, no sobrepasando $2.5 \mathrm{~cm}$ de diámetro, nunca acostillados, esparcidamente pubescentes (al menos cuando inmaduros). Sin embargo, esta especie se distingue fácilmente por carecer de abundantes glándulas rojizas en el envés de los foliolos.

Con base en el trabajo de Coronado (2003) y utilizando los mismos conceptos taxonómicos de Pennington (1981) sobre el complejo de G. glabra, la nueva especie se podría relacionar con $G$. bullata Radlk., G. glabrescens (Hook. \& Arn.) Blake y $G$. petensis Coronado -ined. Sin embargo, estas especies se distinguen igualmente por carecer de abundantes glándulas rojizas en el envés de los foliolos; además, la primera especie muestra mayor número de foliolos, hasta 24 pares, y los frutos tienen pericarpo más grueso, 3-7 mm, mientras las dos últimas presentan hojas con menor número de foliolos, hasta 4(-6) pares, flores estaminadas más pequeñas, con el cáliz hasta $0.5 \mathrm{~mm}$ de largo, los pétalos hasta $6.5 \mathrm{~mm}$ de largo y el tubo estaminal hasta $5 \mathrm{~mm}$ de largo.

EtimologíA. El epíteto adenophylla (griego adenos, glándula, y phyllon, hoja) hace alusión a la presencia de glándulas rojizas y generalmente muy abundantes en el envés de los foliolos.

Especímenes examinados. COSTA RICA. Vertiente Pacífica, Reserva, 1520-1580 m, 27 jul 1987 (fr), V.J. Dryer 1577 (MO). Alajuela: Naranjo, San José, 1400 m, 19 jul 1972 (fl, fr), L.R. Holdridge 6752 (CR). San Ramón, Colinas de Piedades cerca de San Ramón, 21 jun 1927, A.M. Brenes 5472 (CR); Reserva Biológica Manuel Brenes, $1100 \mathrm{~m}, 10^{\circ} 13^{\prime} \mathrm{N}, 84^{\circ} 36^{\prime} \mathrm{W}, 29$ mayo 2002 (fr), J. Homeier 1112 (INB); Upala, Parque Nacional Guanacaste, Estación San Ramón, Dos Ríos, límite del parque, a $2 \mathrm{~km}$ de la casa, $550 \mathrm{~m}$, $10^{\circ} 52^{\prime} 50^{\prime} \mathrm{N}, 85^{\circ} 24^{\prime} 05^{\prime \prime} \mathrm{W}, 27$ ene 1995 (fl), F. Quesada 217 (INB). Guanacaste: Liberia, Parque Nacional Guanacaste, Estación Pitilla, sendero El Mismo, finca La Pasmompa, $700 \mathrm{~m}, 11^{\circ} 02^{\prime} 00^{\prime} \mathrm{N}, 85^{\circ} 24^{\prime} 30^{\prime \prime} \mathrm{W}, 9$ dic 1990 (fr), P. Ríos 267 (INB); Tilarán, Las Nubes, Monte de los Olivos, finca Huber Barquero, $1500 \mathrm{~m}$, 10²2'00'N, 8450'40'W, 10 mar 1993 (fl), E. Bello \& E. Cruz 4877 (INB); Río Chiquito, San Bosco river valley, 1000-1300 m, 10²3'N, 84 ${ }^{\circ} 50^{\prime} \mathrm{W}, 28$ ago 1986 (fr), W. Haber 5583 (CR, MO). Heredia: Sarapiquí, Parque Nacional Braulio Carrillo, Estación El Ceibo, 450-500 m, 10²0’N, 8404'W, 14 mar 2003 (fr), G. González 3152 (INB); 9 km NO de Vara Blanca, Parque Nacional Braulio Carrillo, Estación Murillo, Proyecto ALAS, $1500 \mathrm{~m}, 10^{\circ} 14^{\prime} \mathrm{N}, 8^{\circ} 07^{\prime} \mathrm{W}, 13$ abr 2005 (fr), D. Solano et al. 2169 (CR, INB). Puntarenas: Monteverde, around the Monteverde Nature Reserve, 1450-1650 m, $10^{\circ} 18^{\prime} \mathrm{N}, 84^{\circ} 47^{\prime} \mathrm{W}, 31$ oct 1975 (fl), $W$. Burger 9651 (CR, DUKE, MO); orillas del Pantano Chomogo, 1600-1620, 13 dic 1976 (fr), V.J. Dryer 1055 (CR); Cerro Amigos, 1600-1620 m, 25 ene 1977 (fr), V.J. Dryer 1148 (CR); 1550 m, 1048'N, 8450'W, 22 ago 1984, A. Gentry \& W. Haber 48817 (MO), A. Gentry \& W. Haber 48828 (MO); 12-13 jul 1990, A. Gentry 71564 (MO), A. Gentry 71608 (MO); 1550 m, 23 ene 1979 (fl), W. Haber 274 (CR, MO); upper community, Cambell farm, $1500 \mathrm{~m}, 10^{\circ} 18^{\prime} \mathrm{N}$, 8448'W, 30 jul 1991 (fl, fr), W. Haber 10792 (CR, INB, MO); along Sendero El Río, 1550 m, 18 febr 1978 (fr), G.S. Hartshorn 2120 (CR, MO). PANAMÁ. Bocas del Toro: Campamento La Pata del Cedro, cerca del Río, 1525 m, 0903’N, 8243’W, 14 mar 2004 (fr), E. Alfaro \& A.K. Monro 5557 (INB); along Bocas del Toro-Chiriquí border, Fortuna Dam area, 1200-1300 m, $8^{\circ} 45^{\prime} \mathrm{N}, 82^{\circ} 15^{\prime} \mathrm{W}, 6$ mar 1986 (fr), G. McPherson 8627 (MO).

\section{Guarea aguilarii Al. Rodr., sp. nova}

Guarea aguilarii habitu arborescenti, foliis usque ad 24 foliolorum pares, inflorescentiis caulifloris vel ramifloris, petalis exterius sericeis, ovario solum ad basim pubescenti, duo per loculum superpositis ovulis, fructibus globulosis vel depresso-globulosis, conspicue costulatis dignoscenda.

TIPO: COSTA RICA. Puntarenas; Parque Nacional Corcovado, Llorona to Los Planes, $100 \mathrm{~m}, 8^{\circ} 36^{\prime} \mathrm{N}$, 834', 25 mar 1989 (fr), C. Kernan \& P. Phillips 1020 (Holotipo: INB). Fig. 2.

Árbol entre 13 y $30 \mathrm{~m}$ de altura, dioico. Tronco con corteza interna amarillenta; tallitos ferrugíneopuberulentos en partes terminales, sin lenticelas. Hojas pinnadas, con una yema terminal de crecimiento intermitente; pecíolo 8-13 cm de largo, ferrugíneopuberulento, lado adaxial aplanado y con bordes agudos; raquis $5-180 \mathrm{~cm}$ de largo, ferrugíneopuberulento, subcuadrado, lado adaxial canaliculado, largo entre foliolos 3-12 cm; foliolos 1-24 pares, opuestos, peciólulos $0.4-1.7 \mathrm{~cm}$ de largo x 3-3.5 mm 
de ancho, subteretes; lámina 10-42 cm de largo y 6$17 \mathrm{~cm}$ de ancho, elíptica, oblongo-elíptica a oblongoobovada, base cuneada, menos frecuente obtusa, ápice cuspidado o agudo, adaxial y abaxialmente nada a ligeramente discolora al secar, haz verde-grisáceo a grisáceo, sin o con inconspicuas papilas, envés rojizo a verde-grisáceo, esparcidamente puberulento, sin glándulas rojizas, foliolos próximales levemente reducidos, nervadura eucamptódroma, con 8-17 pares de venas secundarias. Inflorescencias caulifloras o ramifloras, solitarias o bi-trifasciculadas, tirsos estrechos, 5-8 $\mathrm{cm}$ de largo, ramas laterales hasta 3 $\mathrm{cm}$ de largo, generalmente multifloras, péndulas, pedúnculo indefinido o hasta $1 \mathrm{~cm}$ de largo. Flores subsésiles o pedicels hasta $2 \mathrm{~mm}$ de largo, articulado, con 2-3 bracteolas entre 1.5 y $2.5 \mathrm{~mm}$ de largo. Flores estaminadas desconocidas. Flores pistiladas con cáliz 5-6 mm de largo, ciatiforme, puberulento, subtruncado a inconspicuamente denticulado; pétalos 5-6, 15$16 \mathrm{~mm}$ de largo y $1.5-2 \mathrm{~mm}$ de ancho, crema, ápice agudo, lado externo pardo seríceo, interno papilado; tubo estaminal $11-12 \mathrm{~mm}$ de largo y $4.5-5 \mathrm{~mm}$ de ancho, ápice denticulado, lado externo papilado; anterodios 12, 2.25-2.5 mm de largo y 0.3-0.5 mm de ancho, oblongos; ginóforo 1-1.5 mm de largo y 1.5$1.75 \mathrm{~mm}$ de ancho, glabro, nectario $1-1.2 \mathrm{~mm}$ de largo, conspicuo; ovario con 6 a 9 lóculos, 2.5-3 mm de largo y 2-2.5 mm de ancho, con 2 óvulos superpuestos por lóculo, esparcida a densamente seríceo en 1/4-3/4 partes basales, glabrescente en 1/4-3/4 partes distales; pistilo más pequeño o subigual al tubo estaminal, estilo 5-6 mm de largo, glabro, estigma $0.5-0.75 \mathrm{~mm}$ de largo y $2-2.25 \mathrm{~mm}$ de diámetro. Frutos $3-5 \mathrm{~cm}$ de largo y 3-5 $\mathrm{cm}$ de ancho, rojos al madurar, esparcidamente puberulentos, glabrescentes al madurar, globulosos a depreso-globulosos, con 6 a 9 costillas longitudinales, regulares y conspicuas, 6 a 9 lóculos, con lenticelas esparcidas, base obtusa, ápice obtuso a emarginado, ginóforo $c a .2 \mathrm{~mm}$, pericarpo $5-12 \mathrm{~mm}$ de grosor; semillas 2 por lóculo, $1-1.5 \mathrm{~cm}$ de largo, subrodeadas por una sarcotesta anaranjada.

Fenología. Flores en abril y setiembre; frutos en marzo y setiembre.

Distribución. Especie endémica en Costa Rica; se encuentra en bosques húmedos de la vertiente pacífica, en Puriscal-Los Santos, Fila Chonta y Nara y en Península de Osa-Golfito, a elevaciones entre 40 y $700 \mathrm{~m}$.

Guarea aguilarii se reconoce por la combinación de los siguientes caracteres morfológicos: hábito arborescente, hojas grandes, hasta con 24 pares de foliolos, el raquis hasta con $180 \mathrm{~cm}$ de largo, inflorescencias caulifloras a ramifloras, flores (al menos femeninas) con pétalos densamente seríceos en el lado externo, ovario pubescente sólo en su base, con 6 a 9 lóculos, con 2 óvulos superpuestos por lóbulo, y frutos globulosos a depreso-globulosos, conspicuamente acostillados, con el pericarpo duro y grueso.

$\mathrm{Al}$ considerar hábito arborescente, foliolos grandes, flores con pétalos y ovario pubescentes, este último con dos óvulos superpuestos por lóculo y frutos frecuentemente caulifloros o ramifloros y acostillados, G. aguilarii se podría relacionar con las sudamericanas G. carapoides Harms, G. casimiriana Harms y G. corrugata Cuatrec., además, con G. hoffmanniana C. DC. y G. rhopalocarpa Radlk., ambas presentes en Costa Rica. Sin embargo, estas especies se distinguen debido a que tienen hojas con menor número de foliolos, nunca más de 15 pares, las inflorescencias llegan a ser más largas, entre 4 y $45 \mathrm{~cm}$ de largo, los lóbulos del cáliz generalmente son más conspicuos, el ovario es densamente pubescente en toda su extensión y los frutos son piriformes (desconocidos en G. carapoides y G. casimiriana).

Vegetativamente, es difícil distinguir Guarea aguilarii de la simpátrica G. grandifolia debido al hábito, las hojas grandes y el tamaño y la forma de los foliolos. Se diferencian debido a que G. grandifolia tiene corteza interna rosada (vs. amarillenta), las hojas más pequeñas, con el raquis no sobrepasando $110 \mathrm{~cm}$ de largo y los foliolos hasta 17 pares, la lámina de estos últimos también más pequeña, hasta $32 \mathrm{~cm}$ de largo y 10 $\mathrm{cm}$ de ancho y el envés presenta esparcidas y diminutas glándulas rojizas; además, las inflorescencias son evidentemente más grandes, entre 15 y $50 \mathrm{~cm}$ de largo, las flores tienen el ovario densamente pubescente en toda su extensión y los frutos son piriformes y nada a ligeramente acostillados.

Etimología. El epíteto aguilarii es dedicado a Reinaldo Aguilar, botánico costarricense de trayectoria bien conocida, quien ha aportado excelentes especímenes de esta especie; además, como mérito a su tenaz e incansable dedicación al estudio de la flora costarricense, particularmente de su amada Península de Osa.

Especímenes examinados. COSTA RICA. Puntarenas: Osa, Península de Osa, Quebrada Banegas, Aguabuena,

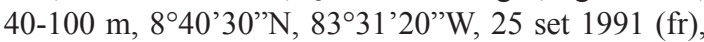
R. Aguilar 476 (INB, MO); fila antes de Rancho Quemado, cerca de Rincón, $300 \mathrm{~m}, 08^{\circ} 42^{\prime} \mathrm{N}, 83^{\circ} 33^{\prime} \mathrm{W}$, 
11 ene 1993, A. Gentry 78671 (INB); Fila Estero

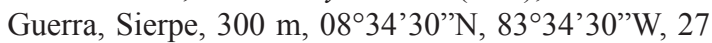
set 1991 (fl), J. Marín 217 (MO). San José: Tarrazú, San Lorenzo, ladera oeste del Río Naranjito, 400$700 \mathrm{~m}, 09^{\circ} 33^{\prime} 10^{\prime \prime} \mathrm{N}, 8^{\circ} 01^{\prime} 15^{\prime}$ 'W, 3 abr 1997 (fl), $J$. Sánchez et al. 748 (CR).

\section{Guarea ciliata Al. Rodr., sp. nova}

Species nova habitu fruticoso, apice foliolorum longo-acuminato, margine foliolorum ciliato, inflorescentiis brevibus et paucifloribus, corola et pistilo glabrescentibus, ovulo uno per ovarii loculum, fructibus globulosis, semine uno per loculum distincta est.

TIPo: COSTA RICA. HEREDIA. Sarapiquí, La Virgen, Estación Biológica La Selva, senderos aledaños a la Estación, $100 \mathrm{~m}, 10^{\circ} 26^{\prime} 00^{\prime \prime} \mathrm{N}, 84^{\circ} 00^{\prime} 30^{\prime \prime} \mathrm{W}, 5$ febr 2004 (fr), A. Rodríguez 8400 (Holotipo: INB, isotipos: CR, F, GH, MO, NY). Fig. 3.

Arbusto entre 2.5 y $4 \mathrm{~m}$ de altura, dioico; tallitos glabrescentes, puberulentos en ramitas terminales, generalmente sin lenticelas. Hojas pinnadas, con yema terminal de crecimiento intermitente; pecíolo 1-7 cm de largo, puberulento, subterete a levemente aplanado en el lado adaxial, sin bordes agudos; raquis 2-60 $\mathrm{cm}$ de largo, puberulento, subcuadrado y levemente canaliculado adaxialmente, largo entre foliolos 2-7 $\mathrm{cm}$; foliolos 1-9 pares, opuestos, peciólulos 0.2-0.6 $\mathrm{cm}$ de largo y $0.75-2.5 \mathrm{~mm}$ de ancho; lámina 3-19 $\mathrm{cm}$ de largo y 1-6 cm de ancho, elíptica, oblongoelíptica, base cuneada, ápice acuminado a cuspidado, adaxial y abaxialmente concolora, verde a verdegrisácea al secar, haz papilado, envés glabro (aunque con tricomas esparcidos y cortos en los nervios principales y en el margen), con glándulas rojizas esparcidas e inconspicas, nervadura eucamptódroma, 6-13 pares de venas secundarias. Inflorescencias axilares, ramifloras, caulifloras o subterminales, solitarias, racemosas, 1-2 cm de largo, paucifloras, erectas, pedúnculo casi indefinido, no sobrepasando 1 $\mathrm{mm}$ de largo. Flores con pedicelo 1-2 mm de largo, articulado y con 1 ó 2 bracteolas entre 0.25 y $0.5 \mathrm{~mm}$ de largo. Flores estaminadas con cáliz $0.75-1 \mathrm{~mm}$ de largo, pateliforme, esparcidamente piloso, lóbulos 4, incisos 1/5 o menos del tamaño del cáliz; pétalos 4, 5$6 \mathrm{~mm}$ de largo y 1.25-1.5 mm de ancho, rosados, ápice agudo, lado externo glabrescente a esparcidamente pubescente en la parte distal, interno papilado; tubo estaminal $4-4.5 \mathrm{~mm}$ de largo y $1.75-2 \mathrm{~mm}$ de ancho, ápice crenulado, lado externo papilado; anteras 8, 0.5$0.6 \mathrm{~mm}$ de largo y $0.25-0.4 \mathrm{~mm}$ de ancho; ginóforo $0.5-0.75 \mathrm{~mm}$ de largo y $0.3-0.5 \mathrm{~mm}$ de ancho, glabro, nectario $0.25 \mathrm{~mm}$ de largo, levemente conspicuo; ovario $0.5-0.75 \mathrm{~mm}$ de largo y $0.5-0.75 \mathrm{~mm}$ de ancho, glabrescente o con tricomas esparcidos. Pistilo igual o sobrepasando levemente el tubo estaminal, estilo 1.75$2 \mathrm{~mm}$ de largo, glabro, estigma $0.25-0.4 \mathrm{~mm}$ de largo y $0.75-1 \mathrm{~mm}$ de ancho. Flores pistiladas no observadas. Frutos 1-2 cm de largo y 1-2 cm de ancho, globulosos, no acostillados, sin lenticelas, rojizos al madurar, esparcidamente pubescentes (glabrescentes con la edad), base obtusa, ápice obtuso a subtruncado, tetra o pentalocular, pericarpo $0.5-1.5 \mathrm{~mm}$ de grosor, ginóforo 0.5-1.5 mm de largo; semillas 1 por lóculo, ca. 1-1.5 $\mathrm{cm}$ de largo, subrodeadas por la sarcotesta.

Distribución. Costa Rica y Nicaragua. En ambos países habita en bosques húmedos de la vertiente caribe, en Nicaragua en la cuenca del Río San Juan, en la zona limítrofe con Costa Rica; en este país se conoce de las Llanuras de San Carlos y de Tortuguero, entre 0 y $200 \mathrm{~m}$.

Fenología. Flores en abril, junio, agosto y noviembre; frutos en febrero, marzo, mayo, julio y octubre.

Guarea ciliata se reconoce por la combinación de los siguientes caracteres morfológicos: hábito arbustivo, partes vegetativas puberulentas (al menos notorio en ramitas terminales), foliolos con el ápice generalmente largo-acuminado, envés glabrescente, margen ciliado, principalmente en hojas nuevas, haz diminutamente papilado, inflorescencias racemosas, cortas y paucifloras, flores con pétalos esparcidamente pubescentes hacia el ápice, corola y pistilo glabrescente, ovario tetra o pentalocular, con un óvulo por lóculo, frutos globulosos, tetra o pentaloculares, con una semilla por lóculo.

Esta especie se podría relacionar con $G$. excelsa Kunth, G. gentryi Coronado -ined, G. glabra Vahl, G. kegelii Turcz., G. luxii C. DC. y G. tuerckheimii C. DC., al considerar conceptos taxonómicos de Coronado (2003), que incluyen cáliz denticulado, pétalos esparcidamente pubescentes, ovario (tri)tetra(-penta)locular, glabro y con un óvulo por lóculo. Sin embargo, estas especies se diferencian debido a que son árboles que generalmente alcanzan mayor tamaño, entre 3 y $35 \mathrm{~m}$ de altura, las hojas a menudo presentan domacios de tricomas en el envés (excepto en $G$. kegelii) y las inflorescencias en la mayoría de los casos son paniculadas, multifloras y más grandes, 
(1-)6-20 cm. Además, G. excelsa y G. kegelii tienen pétalos más grandes, entre 7 y $9 \mathrm{~mm}$ de largo; G. luxii y G. tuerckheimii con frecuencia presentan mayor número de foliolos, hasta 12 pares, mientras que $G$. gentryi es distintiva porque tiene flores masculinas muy pequeñas, con pétalos entre 3 y $4 \mathrm{~mm}$ de largo, y tubo estaminal entre 2 y $3 \mathrm{~mm}$ de largo.

Etimología. El epíteto latino ciliata hace referencia a los cilios o tricomas presentes en el margen de las hojas, principalmente en las nuevas.

Especímenes examinados. NICARAGUA. Río San Juan: a lo largo del Río San Juan entre El Tambor y Remolinos, incluyendo el caño de San Francisco, 50-200 m, $10^{\circ} 45^{\prime} \mathrm{N}, 84^{\circ} 01^{\prime} \mathrm{W}, 10$ jul 1994 (fr), R. Rueda et al. 1903 (MO). COSTA RICA. Alajuela: San Carlos, Pital, Boca Tapada, Finca Pipasa, Parcela Pipasa, 50-100 m, $10^{\circ} 41^{\prime} 10^{\prime \prime} \mathrm{N}, 84^{\circ} 10^{\prime} 50^{\prime \prime} \mathrm{W}, 21$ mayo 2005 (fr), D. Solano 2771 (INB). Heredia: Puerto Viejo, Estación Biológica La Selva, 50-80 m, $10^{\circ} 26^{\prime} \mathrm{N}, 84^{\circ} 01^{\prime} \mathrm{W}, 8$ abr 1988 (fl), G. Chaverri 287 (INB, MO); south of Puerto Viejo, 5 febr 1983 (fr), N. Garwood, M. Gibby, R. Hamshire \& C. Humphries 1113 (CR); Finca La Selva, the OTS field station on the Río Puerto Viejo just E of its junction with Río Sarapiquí, 25 ago 1979 (fl), M.H. Grayum 2525 (DUKE, MO); 11 mar 1980 (fr), B. Hammel 8051 (CR, DUKE); 2 nov 1980 (fl), B. Hammel 10339 (DUKE); Paso Perdido trail cut, 25 jun 1984 (fl), Jacobs \& Smith 2568 (DUKE); camino al lindero sur, $0-100 \mathrm{~m}, 10^{\circ} 26^{\prime} \mathrm{N}, 84^{\circ} 02^{\prime} \mathrm{W}, 1$ oct 2003 (fr), $R$. Kriebel et al. 3985 (INB).

\section{Guarea constricta Al. Rodr., sp. nova}

Species nova haec ab alteribus speciebus generis Guareae fructibus leviter et transverse inter semina constrictis, floribus fructibusque glabrescentibus, ovario tetraloculari, loculis cum duobus superpositis ovulis differt.

Tipo: COSTA RICA. San José; Pérez Zeledón, Savegre Abajo de Río Nuevo, finca de Victor Julio Mena, 700$1000 \mathrm{~m}, 9^{\circ} 27^{\prime} 20^{\prime \prime} \mathrm{N}, 8^{\circ} 50^{\prime} 30^{\prime \prime} \mathrm{W}, 10$ febr 1999 (fl), A. Estrada 2016 (Holotipo: CR, isotipos: INB, MO). Fig. 4.

Árbol entre 6 y $20 \mathrm{~m}$ de altura. Tronco con corteza interna rosado pálido; tallitos glabrescentes y esparcidamente lenticelados. Hojas pinnadas, con una yema terminal de crecimiento intermitente; pecíolos
5-24 cm de largo, glabros, lado adaxial levemente aplanado, con bordes agudos únicamente hacia la base; raquis $5-40 \mathrm{~cm}$ de largo, glabro, subcuadrado, levemente canaliculado adaxialmente, largo entre foliolos 4-13 cm; foliolos 1-5 pares, opuestos, peciólulos $1-1.5 \mathrm{~cm}$ de largo y $1.5-5 \mathrm{~mm}$ de ancho; lámina $17-50 \mathrm{~cm}$ de largo y $7-20 \mathrm{~cm}$ de ancho, elíptica a obovada, base cuneada, menos frecuente obtusa, ápice agudo o cuspidado, adaxial y abaxialmente concolora, verde a verde-grisácea al secar, haz sin papilas, envés glabrescente y carente de glándulas rojizas, nervadura eucamptódroma, 6-20 pares de venas secundarias. Inflorescencias axilares o ramifloras, solitarias a fasciculadas, cimas paniculadas, 3-25 cm de largo, ramas laterales hasta $6 \mathrm{~cm}$ de largo, paucifloras a multifloras, erectas, pedúnculo desde casi indefinido hasta $5 \mathrm{~cm}$ de largo. Flores con pedicelos entre 1 y 5 $\mathrm{mm}$ de largo, articulados, con 1 ó 2 bracteolas entre 0.25 y $0.75 \mathrm{~mm}$ de largo. Flores estaminadas con cáliz 3.5-4.5 mm de largo, ciatiforme, glabrescente, lóbulos 3-4, levemente incisos o hasta $1 / 4$ el tamaño del cáliz; pétalos 4, 14-16 mm de largo y 2.5-3.5 mm de ancho, blancos, ápice agudo, lado externo glabro, interno papilado; tubo estaminal $12.5-14 \mathrm{~mm}$ de largo y 3-4 mm de ancho, ápice crenulado, lado externo papilado; anteras $8,1.75-2 \mathrm{~mm}$ de largo y $0.3-0.5 \mathrm{~mm}$ de ancho; ginóforo 1.25-1.5 mm de largo y 1-1.25 $\mathrm{mm}$ de ancho, glabro, nectario 1-1.25 $\mathrm{mm}$ de largo, levemente conspicuo; ovario 5-6 mm de largo y 1.75 $2 \mathrm{~mm}$ de ancho, glabro; pistilo igual o sobrepasando levemente el tubo estaminal, estilo 3-4 $\mathrm{mm}$ de largo, glabro, estigma $0.5-0.7 \mathrm{~mm}$ de largo y $c a .1 .5 \mathrm{~mm}$ de diámetro. Flores pistiladas con cáliz 3.5-4 mm de largo, ciatiforme, glabrescente, lóbulos 4-5, irregularmente partidos, incisos $c a$. 1/4 del tamaño del cáliz; pétalos 4, 10-15 mm de largo y 2-2.5 mm de ancho, blancos, ápice agudo, lado externo glabro, interno papilado hacia la parte distal; tubo estaminal $9-14 \mathrm{~mm}$ de largo y 4-4.5 mm de ancho, ápice denticulado, lado externo glabro; anteroides 9, 1.5-1.75 $\mathrm{mm}$ de largo; ginóforo 1.75-2 $\mathrm{mm}$ de largo y 1-1.2 $\mathrm{mm}$ de ancho, glabro, nectario apenas diferenciado; ovario glabro, tetralocular, lóculos con 2 óvulos superpuestos; pistilo subigual al tubo estaminal, estilo $4-5 \mathrm{~mm}$ de largo, estigma $0.5-0.7 \mathrm{~mm}$ de largo y $1.25-1.5 \mathrm{~mm}$ de diámetro. Frutos $4-7 \mathrm{~cm}$ de largo y $2-4 \mathrm{~cm}$ de ancho, piriformes, no acostillados, levemente constrictos entre las semillas (notorio principalmente en material seco), con lenticelas esparcidas, base atenuada, ápice obtuso, glabros, tetraloculares, ginóforo $2.5-3 \mathrm{~mm}$ de largo, grosor del pericarpo no observado; semillas no observadas. 
Distribución. Especie endémica en Costa Rica; habita en bosques húmedos de la vertiente pacífica en Puriscal-Los Santos, Tárcoles-Térraba, Fila Costeña Norte, Fila Costeña Sur y Península de Osa, entre 150 y 1140 m de elevación.

Fenología. Flores en enero, febrero, marzo y junio; frutos en marzo y abril.

Guarea constricta se distingue de otras especies de Guarea por mostrar frutos leve y transversalmente constrictos entre las semillas (notorio principalmente en frutos maduros y secos); además, se caracteriza por ser una especie arborescente, con foliolos muy grandes (aunque no produce más de cinco pares por hoja), partes vegetativas, flores y frutos glabrescentes, flores con ovario tetralocular, lóculos con dos óvulos superpuestos y frutos piriformes no acostillados.

En la Amazonia de Brasil y Perú se encuentra otra especie con frutos constrictos, G. guentheri Harms, pero se diferencia ya que muestra pétalos y ovario pubescentes y envés de las hojas esparcidamente pubescente con papilas rojizas. Esta especie se podría relacionar con la ampliamente distribuida G. kunthiana A. Juss. y la sudamericana G. silvatica C. DC. por presentar ovario glabro, tetralocular, con dos óvulos superpuestos por lóculo. Sin embargo, G. kunthiana se distingue ya que las hojas presentan mayor número de foliolos, hasta 10 pares, los pecíolos son más cortos, no sobrepasan $8 \mathrm{~cm}$ de largo, las inflorescencias tienen ramas laterales más largas, hasta $21 \mathrm{~cm}$ de largo, los pétalos son ferrugíneo-seríceos en el lado externo, las flores masculinas tienen el tubo estaminal más corto, entre 7 y $10 \mathrm{~mm}$ de largo, y los frutos son elipsoides, nunca constrictos. G. silvatica se diferencia por frutos testiculados, inflorescencias con ramas laterales casi obsoletas y ovario con frecuencia bi o trilocular. $G$. constricta también se puede comparar con $G$. inesiana Al. Rodr. (ver comentarios bajo esta especie).

Etimología. El epíteto latino constricta hace referencia a los frutos constrictos que caracterizan a esta especie.

Especímenes examinados. COSTA RICA. Puntarenas: Puntarenas: Golfito, Parque Nacional Esquinas, Fila Costeña Cruces, $500 \mathrm{~m}, 08^{\circ} 41^{\prime} \mathrm{N}, 83^{\circ} 15^{\prime} \mathrm{W}, 27$ mar 1999 (fl), W. Huber \& A. Weissenhofer 1566 (CR); Península de Osa, Reserva Forestal Golfo Dulce, trocha de La Tarde rd. $10 \mathrm{~km} \mathrm{SW}$ of La Palma, S of Rincón de Osa, 150-200 m, 08³7'N, 83² $28^{\prime} \mathrm{W}, 28$ abr 1988 (fr), B. Hammel 16760 (INB, MO). San José: Dota, San Isidro, $2 \mathrm{~km}$ antes de San Isidro, 600700, 09²9'00'N, 8401'20'W, 4 mar 2005 (fr), D.
Santamaría 934 (INB); Pérez Zeledón, Tinamaste, Finca Los Suizos, 650 m, 09¹7'54”N, 8346’20”W, 13 abr 1999 (fr), A. Estrada 2165 (CR); Finca Tinamaste, 1140 m, 24 abr 1997 (fr), A. Rodríguez 2139 (INB); Puriscal, Santa Rosa, Zona Protectora La Cangreja, 500 m, 0942'28'N, 84²3'38'W, 6 ene 1993 (fl), J.F. Morales 1028 (INB); Tarrazú, San Lorenzo, Quebrada Salitrillo, a $1 \mathrm{~km}$ del cruce de San Isidro y la ruta del Cerro Nara, 09²8'27’N, 8402'10'W, 20 may 2005 (fr), A. Rodríguez 9617 (INB).

\section{Guarea corticosa Al. Rodr., sp. nova}

Guarea corticosa habitu fruticoso, monopodico vel pauper ramificato, ramulis suberosis, foliolis magnis, inflorescentiis caulifloris, brevibus, paucifloris, corola pistiloque dense pubescentibus, duo superpositis ovulis per ovarii loculum, fructibus costulatis, seminibus duobus per loculum differt.

TIPo: COSTA RICA. Puntarenas; Reserva Forestal Golfo Dulce, Rincón de Osa, Quebrada Banegas, 40 100 m, 840'25”N, 83³1'20”W, 25 sept 1991 (fr), $R$. Aguilar 488 (Holotipo: INB, isotipo: MO). Fig. 5.

Arbusto entre 2 y $3 \mathrm{~m}$ de altura, monopódico a cortamente ramificado, dioico. Tronco con lado externo de la corteza suberoso; tallitos glabrescentes a esparcidamente puberulentos en ramitas terminales, con lenticelas esparcidas. Hojas pinnadas, con una yema terminal de crecimiento intermitente; pecíolos 5-12 cm de largo, puberulentos a glabrescentes con la edad, lado adaxial aplanado y con bordes agudos; raquis $5-70 \mathrm{~cm}$ de largo, puberulento a glabrescente con la edad, terete a subcuadrado y levemente canaliculado en el lado adaxial, largo entre foliolos 3$15 \mathrm{~cm}$; foliolos 1-7 pares, opuestos, peciólulos 0.2-0.5 cm de largo y 3-4.5 mm de ancho; lámina $10-38 \mathrm{~cm}$ de largo y 5-20 cm de ancho, elíptica a obovado-elíptica, base cuneada, ápice cuspidado a corto acuminado, abaxial y adaxialmente concolora, verde-grisácea a verde-pajiza al secar, en ocasiones levemente discolora, haz diminutamente papilado, principalmente hacia el nervio central, en ocasiones papilas ausentes, envés glabrescente, con glándulas rojizas diminutas y esparcidas, foliolos proximales levemente reducidos, nervadura eucamptódroma, 7-19 pares de venas secundarias. Inflorescencias axilares, ramifloras o caulifloras, solitarias a trifasciculadas, racemosas a cimosas, 1-4 cm de largo, paucifloras, más o menos erectas, pedúnculo indefinido. Flores subsésiles o pedicelos hasta $2 \mathrm{~mm}$ de largo, articulados, con 1 
ó 2 bracteolas entre 0.25 y $0.5 \mathrm{~mm}$ de largo. Flores estaminadas con cáliz 3.5-4.5 mm de largo, ciatiforme, adpreso, esparcida y cortamente pubescente, lóbulos 3-4, hasta 1/4 del tamaño del cáliz; pétalos 4, 11-12.5 $\mathrm{mm}$ de largo y $1.75-2.5 \mathrm{~mm}$ de ancho, crema, ápice agudo, lado externo pardo-seríceo, interno papilado, principalmente hacia la parte distal; tubo estaminal 9.5-10.5 mm de largo y 3-3.5 mm de ancho, ápice crenulado, lado externo papilado; anteras 8, 1.75-2 $\mathrm{mm}$ de largo y $0.3-0.5 \mathrm{~mm}$ de ancho; ginóforo 1-1.25 $\mathrm{mm}$ de largo y $0.8-1.25 \mathrm{~mm}$ de ancho, glabro, nectario inconspicuo; ovario 2-2.5 mm de largo y $1.5-1.7 \mathrm{~mm}$ de ancho, seríceo; pistilo sobrepasando levemente el tubo estaminal, estilo $6-6.5 \mathrm{~mm}$ de largo, seríceo, estigma $c a .0 .8 \mathrm{~mm}$ de largo y $c a .1 \mathrm{~mm}$ de ancho. Flores pistiladas con cáliz 3-4 mm de largo, ciatiforme, adpreso, esparcida y cortamente pubescente, lóbulos 46, apenas definidos o hasta $1 / 4$ del tamaño del cáliz; pétalos 4-5, 11-12 $\mathrm{mm}$ de largo y 2.5-3 $\mathrm{mm}$ de ancho, crema, ápice agudo, lado externo pardo-seríceo, interno papilado, principalmente hacia la parte distal; tubo estaminal 7-8 mm de largo y $c a .3 .5 \mathrm{~mm}$ de ancho, ápice crenado, lado externo glabro; anteroides $8-9,1.25-1.5 \mathrm{~mm}$ de largo y $0.45-0.6 \mathrm{~mm}$ de ancho; ginóforo $0.75-1 \mathrm{~mm}$ de largo y $c a .1 .5 \mathrm{~mm}$ de ancho, glabro, nectario $0.3-0.5 \mathrm{~mm}$ de largo, inconspicuo; ovario seríceo, con 4-6(-8) lóculos, 2-2.5 mm de largo y 2-2.5 mm de ancho, con 2 óvulos superpuestos por lóculo; pistilo subigual al tubo estaminal, estilo 2.5-3 $\mathrm{mm}$ de largo, seríceo, estigma $0.5-0.75 \mathrm{~mm}$ de largo y 1-1.25 mm de ancho. Frutos 2-4 cm de largo y 2$3 \mathrm{~cm}$ de ancho, globulosos a globuloso-piriformes, con numerosas costillas longitudinales, conspicuas e irregulares, lenticelas ausentes, base obtusa, truncada a cuneada, ápice obtuso, truncado o emarginado, con 46(-8) lóculos, ginóforo puberulento, $c a .1 \mathrm{~mm}$ de largo, pericarpo $1-5 \mathrm{~mm}$ de grosor; semillas 2 por lóculo, 0.8-1.2 cm de largo, subrodeadas por la sarcotesta, con frecuencia algunas estériles.

Distribución. Endémica en Costa Rica; habita en bosques húmedos de la vertiente pacífica en PuriscalLos Santos y Península de Osa-Golfito, entre 100 y $500 \mathrm{~m}$.

FEnología. Flores en febrero y mayo; frutos en febrero y setiembre.

Guarea corticosa se distingue de otras especies del género, exceptuando la sudamericana G. carinata Ducke, por mostrar tallitos suberosos (notorio principalmente en plantas vivas); además, se caracteriza por el hábito arbustivo, monopódico a poco ramificado, foliolos grandes hasta en siete pares, con peciólulos reducidos, la mayoría de inflorescencias caulifloras, producidas desde la base del tronco, cortas, paucifloras, y flores con corola y pistilo densamente pubescentes, ovario con 4-6(-8) lóculos, lóculos con dos óvulos superpuestos, frutos solitarios, con numerosas costillas longitudinales, conspicuas e irregulares, y dos semillas por lóculo.

Esta especie está estrechamente relacionada con la sudamericana G. carinata por la corteza suberizada, flores con pétalos seríceos, ovario pubescente, con (4-) 5-6(-8) lóculos, lóculos con dos óvulos superpuestos y frutos conspicua e irregularmente acostillados. Se diferencian porque $G$. carinata tiene hábito arborescente, entre 8 y $22 \mathrm{~m}$ de altura, ramitas terminales, pecíolos, raquis de las hojas, envés de los foliolos y frutos (al menos cuando inmaduros) densamente pubescentes, pardo a ferrugíneo velutino, foliolos generalmente más pequeños, hasta $27 \mathrm{~cm}$ de largo y $9(-12) \mathrm{cm}$ de ancho, inflorescencias no producidas desde la base del tronco y pétalos más largos, entre 14 y $17 \mathrm{~cm}$.

También G. cristata T.D. Penn., de Sudamérica, y G. macrocalyx, endémica en Costa Rica, son especies afines a $G$. corticosa debido a que poseen flores con pétalos seríceos, ovario tetra a hexalocular, pubescente, lóculos con dos óvulos superpuestos y frutos conspicua e irregularmente acostillados. Ambas especies son fáciles de distinguir de G. corticosa, ya que carecen de corteza suberizada y las inflorescencias no se producen desde la base del tronco; además, $G$. cristata tiene foliolos más pequeños, hasta $26 \mathrm{~cm}$ de largo y $5.5 \mathrm{~cm}$ de ancho, y más numerosos, hasta 13 pares, la nervadura es braquidódroma y los frutos tienen costillas más conspicuas, casi como alas; mientras tanto, G. macrocalyx se distingue por flores con cáliz de gran tamaño, (6-)10-15 mm (al menos en flores masculinas), bi o trilobado, lóbulos con una o dos carinas evidentes y con un ápice espinuloso, peciólulos más largos, hasta $2 \mathrm{~cm}$, e inflorescencias más largas, hasta $16 \mathrm{~cm}$.

Material de esta especie ha sido erróneamente identificado como la simpátrica G. grandifolia DC.; sin embargo, los árboles de esta especie alcanzan mayor altura, entre 9 y $25 \mathrm{~m}$, las hojas tienen mayor número de foliolos, hasta 17 pares, las inflorescencias son conspicuamente más grandes, entre 15 y 50 $\mathrm{cm}$ de largo, y los frutos son nada a ligeramente acostillados.

Etimología. El epíteto latino corticosa (= corchosa, del latín cortex, corteza o corcho) hace alusión a la 
corteza notablemente suberizada.

Especímenes examinados. COSTA RICA. Puntarenas: Reserva Forestal Golfo Dulce, Rincón, entrada a Chocuaco, 100-120 m, 0844'00”N, 83²6’40”W, 4 sept 1991 (fr), R. Aguilar 312 (INB); Parque Nacional Corcovado, Los Planes, bosque comunal La Gloria, $100-120 \mathrm{~m}, 08^{\circ} 37^{\prime} 30^{\prime \prime} \mathrm{N}, 83^{\circ} 40^{\prime} 50^{\prime \prime} \mathrm{W}, 16$ febr 1991 (fl, fr), G. Cordero 253 (INB, MO); camino entre Rincón y Rancho Quemado, $100 \mathrm{~m}, 08^{\circ} 40^{\prime} 10^{\prime \prime} \mathrm{N}, 83^{\circ} 30^{\prime} 30^{\prime \prime} \mathrm{W}$, 29 mayo 2003 (fl), A. Rodríguez 8011 (INB).

\section{Guarea inesiana Al Rodr., sp. nova}

A omnibus speciebus generis Guareae domatiis patentibus sub foliolis, floribus cum duobus per loculum superpositis ovulis fructibusque per loculum duobus seminibus continentibus distinguenda.

Tipo: COSTA RICA. San José; Dota, Copey,

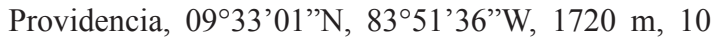
jun 2005 (fr), A. Rodríguez 9624 (Holotipo: INB, isotipos: $\mathrm{CR}, \mathrm{GH}, \mathrm{MO})$. Fig. 6.

Árbol entre 15 y $35 \mathrm{~m}$ de altura, dioico. Tronco con corteza interna rosada; tallitos puberulentos, al menos en ramitas terminales, esparcidamente lenticelados. Hojas pinnadas, con una yema terminal de crecimiento intermitente, con frecuencia obsoleta en hojas viejas; pecíolos 2-10 $\mathrm{cm}$ de largo, esparcidamente puberulentos, glabrescentes con la edad, aplanados a subteretes en hojas viejas, bordes levemente agudos; raquis $3-45 \mathrm{~cm}$ de largo, glabrescente, aplanado y ligeramente canaliculado en el lado adaxial, subterete con la edad, largo entre foliolos 2-7 cm; foliolos 1-9 pares, opuestos, peciólulos $0.5-1.5 \mathrm{~cm}$ de largo y 2.5$4.5 \mathrm{~mm}$ de ancho; lámina 9-33 $\mathrm{cm}$ de largo y 5-12.5 $\mathrm{cm}$ de ancho, oblongo-elíptica, oblongo-obovada u oblongo-lanceolada, adaxial y abaxialmente concolora, verde-grisácea a rojizo-grisácea al secar, haz sin papilas, envés grabrescente, aunque con conspicuos domacios de tricomas en las axilas formadas en el cruce de la vena central con las secundarias, sin glándulas rojizas, base obtusa o cuneada, ápice agudo o cuspidado, nervadura eucamptódroma, 6-16 pares de venas secundarias. Inflorescencias axilares o ramifloras, solitarias o pareadas, paniculadas, 5$8 \mathrm{~cm}$ de largo, ramas laterales hasta $5 \mathrm{~cm}$ de largo, multifloras, erectas, pedúnculo hasta $1 \mathrm{~cm}$ de largo, aunque con frecuencia indefinido. Flores con pedicelos 1-5 mm de largo, articulado, con un par de bracteolas entre 0.7 y $1.25 \mathrm{~mm}$ de largo. Flores estaminadas con cáliz 2.5-3.5 mm de largo, ciatiforme, esparcida y diminutamente estrigoso, lóbulos 3-4, incisos entre 1/5 y 1/4 del tamaño del cáliz; pétalos 4 , blancos, 12-15 $\mathrm{mm}$ de largo y $2.5-5 \mathrm{~mm}$ de ancho, ápice agudo, lado externo glabrescente a esparcidamente pubescente en la parte distal, interno papilado; tubo estaminal 10-13 $\mathrm{mm}$ de largo y 4-6 $\mathrm{mm}$ de ancho, ápice subtruncado a diminutamente denticulado, lado externo papilado; anteras 8-9, 1.5-1.75 mm de largo y 0.6-0.75 mm de ancho; ginóforo glabro, $1.25-1.5 \mathrm{~mm}$ de largo y 1.5-1.75 mm de ancho, nectario 1-1.5 mm de largo, levemente conspicuo; ovario 3-4 mm de largo y 2-2.5 $\mathrm{mm}$ de ancho, glabro; pistilo igual o sobrepasando levemente el tubo estaminal, estilo $5.5-6 \mathrm{~mm}$ de largo, glabro, estigma $0.5-0.9 \mathrm{~mm}$ de largo y $1.5-1.75$ $\mathrm{mm}$ de diámetro. Flores pistiladas con cáliz 2.5-3.5 $\mathrm{mm}$ de largo, pateliforme a ciatiforme, esparcida y diminutamente estrigoso, lóbulos 4 , incisos entre $1 / 4$ y 1/2 del tamaño del cáliz; pétalos 4, 11-12 mm de largo y $c a .2 .5 \mathrm{~mm}$ de ancho, ápice agudo, lado externo glabrescente a esparcidamente pubescente en la parte distal, interno papilado; tubo estaminal $8.5-10 \mathrm{~mm}$ de largo y 4-5 mm de ancho, ápice crenulado, lado externo papilado; anteroides 8-9, 1-1.25 mm de largo y ca. 0.3 $\mathrm{mm}$ de ancho; ginóforo glabro, 0.8-1 $\mathrm{mm}$ de largo y $c a$. $2 \mathrm{~mm}$ de ancho, nectario $c a .1 \mathrm{~mm}$, inconspicuo; ovario tetralocular, 2-2.5 mm de largo y 2.5-3 $\mathrm{mm}$ de ancho, glabrescente o con tricomas diminutos y esparcidos, lóculos con 2 óvulos superpuestos; pistilo subigual o excediendo levemente el tubo estaminal, estilo 3.5-4 $\mathrm{mm}$ de largo, glabro, estigma ca. $0.3 \mathrm{~mm}$ de largo y ca. $0.75 \mathrm{~mm}$ de ancho. Frutos 5-8 cm de largo y 5$8 \mathrm{~cm}$ de ancho, elipsoides, no acostillados, a menudo lenticelados, rojos al madurar, glabros, tetraloculares, ginóforo 3-4 $\mathrm{mm}$ de largo, base y ápice obtusos, pericarpo 10-15 mm de grosor; semillas 2 por lóculo, 1.5-2.5 cm de largo, subrodeadas por la sarcotesta.

Distribución. Especie endémica en Costa Rica; notablemente rara, habita en los bosques pluviales de la vertiente pacífica en la Cordillera Central (Bosque Eterno de los Niños, Grecia) y en la Cordillera de Talamanca (San Gerardo y Providencia, Dota), 1680$1720 \mathrm{~m}$.

Fenología. Flores en enero y marzo; frutos en marzo y junio.

Guarea inesiana se reconoce fácilmente entre otras especies del género por la combinación de los siguientes caracteres: domacios conspicuos en el envés de los foliolos, flores con dos óvulos superpuestos por lóculo y frutos con dos semillas por lóculo; además, se 
caracteriza por hábito arborescente, flores con pétalos glabrescentes a esparcidamente pubescentes en la parte distal, pistilo glabro a glabrescente y frutos grandes, elipsoides, no acostillados, glabros y con un pericarpo grueso y leñoso.

Esta especie está relacionada con G. kunthiana A. Juss. por las flores con ovario tetralocular, glabro, con dos óvulos superpuestos por lóculo, y frutos elipsoides. Sin embargo, G. kunthiana se distingue porque carece de domacios en el envés de los foliolos, las inflorescencias y ramas laterales son más largas (las primeras hasta $35 \mathrm{~cm}$, las segundas hasta $21 \mathrm{~cm}$ ), las flores femeninas tienen pétalos ferrugíneo-seríceos en el lado externo, el ginóforo llega a ser más largo (1.25$1.5 \mathrm{~mm}$ ) y los frutos son generalmente más pequeños (2-5 cm) y con un pericarpo más delgado (3-9 $\mathrm{mm})$.

Guarea inesiana también es afín a G. constricta, especie aquí descrita, por las flores con pétalos glabros, ovario tetralocular, glabro, con dos óvulos superpuestos por lóculo. Guarea constricta se distingue por las hojas con menor número de foliolos (hasta 5 pares), ausencia de domacios y frutos piriformes, levemente constrictos entre las semillas.

Según Coronado (2003), otras especies frecuentemente observadas con domacios son G. chiricana Standl., G. excelsa Kunth, G. microcarpa C. DC. y la inédita G. gentryi Coronado, pero se distinguen ya que todas presentan ovario unilocular y frutos más pequeños, con sólo una semilla por lóculo. Especímenes de herbario de esta especie han sido erróneamente identificados como G. excelsa, G. glabra Vahl, G. grandifolia DC. y G. kunthiana.

Etimología. El epíteto de esta especie, inesiana, está dedicado a Inés González, mi madre, por su apoyo constante en mi diario caminar.

Especímenes examinados. COSTA RICA. Alajuela: Grecia, Bosque Eterno de los Niños, sendero hacia el Río Achiote, $10^{\circ} 08^{\prime} 30^{\prime \prime} \mathrm{N}, 84^{\circ} 14^{\prime} 50^{`} \mathrm{~W}, 1680$ m, 24 ene 1995 (fl), L. Acosta 1680 (INB); Quebrada Achiote, 4 mar 1959, San Román s.n. (CR-36677), San Román s.n (CR-201084); Reserva Forestal Grecia, Bosque Eterno de los Niños, Sendero Pinares, $10^{\circ} 08^{\prime} 40^{\prime \prime} \mathrm{N}$, $84^{\circ} 15^{\prime} 01^{\prime \prime} \mathrm{W}, 1740 \mathrm{~m}, 30$ de mar 2006 (fl), L.D. Vargas 1233 (INB). San José: Santa María de Dota, 24 jun 1994 (fr), L. González 146 (CR).

\section{Guarea macrocalyx Al. Rodr., sp. nova}

Species novae haec a omnibus speciebus generis Guareae florum calyce permagno, bi- vel trilobato, magnitudini lobulorum regulari, uni vel bicarinatis, ad apicem spinulosis dignoscenda est.

TIPO: COSTA RICA. San José; Pérez Zeledón, Tinamaste, Finca de los Suizos, $700 \mathrm{~m}, 09^{\circ} 17^{\prime} 54^{\prime \prime} \mathrm{N}$, 8346’20”'W, 9 jun 1997, (fl) A. Estrada 832 (Holotipo: CR, isotipo: INB). Fig. 7.

Arbusto o árbol entre (1.5-)3 y $8 \mathrm{~m}$ de altura. Tallitos pardo-puberulentos en ramitas terminales, aunque glabrescentes con la edad, con o sin lenticelas esparcidas. Hojas pinnadas, con una yema terminal de crecimiento intermitente; pecíolos 9-20 cm de largo, puberulentos, lado adaxial aplanado y con bordes agudos; raquis 20$50 \mathrm{~cm}$ de largo, puberulento, subcuadrado y levemente canaliculado en el lado adaxial, largo entre foliolos 3-10 cm; foliolos 1-7 pares, opuestos o subopuestos, peciólulos $1.2-2 \mathrm{~cm}$ de largo y 2-3 $\mathrm{mm}$ de ancho; lámina $12-31 \mathrm{~cm}$ de largo y $7-16 \mathrm{~cm}$ de ancho, oblongoelíptica a oblongo-lanceolada, adaxial y abaxialmente concolora, verde-grisácea al secar, haz con papilas restringidas al nervio central, envés glabrescente, con glándulas rojizas diminutas y esparcidas, base cuneada a obtusa, ápice cuspidado, nervadura eucamptódroma, 10-17 pares de venas secundarias. Inflorescencias axilares o ramifloras, solitarias, tirsos estrechos de apariencia racemosa, $11-25 \mathrm{~cm}$ de largo, ramas laterales hasta $5 \mathrm{~cm}$ de largo, multifloras, erectas o péndulas, pedúnculo hasta $c a .0 .5 \mathrm{~cm}$ de largo, en ocasiones indefinido. Flores con pedicelo entre 2 y $5 \mathrm{~mm}$ de largo, articulado, con 1 ó 2 bracteolas entre 5 y $7 \mathrm{~mm}$ de largo. Flores estaminadas con cáliz (6-)10-14 mm de largo, ciatiforme, esparcidamente puberulento, bi o trilobado, lóbulos irregulares y profundamente partidos, incisos 1/2-5/4 del tamaño del cáliz; pétalos 4-6, blancos, $12-14 \mathrm{~mm}$ de largo y $3.5-5 \mathrm{~mm}$ de ancho, ápice agudo, lado externo seríceo, interno papilado hacia la parte distal; tubo estaminal $c a .9 \mathrm{~mm}$ de largo y ca. 4 $\mathrm{mm}$ de ancho, ápice crenulado, lado externo papilado; anteras 8-9, 1.75-2.5 mm de largo y 0.4-0.6 $\mathrm{mm}$ de ancho; ginóforo glabro, $0.4-0.75 \mathrm{~mm}$ de largo y $1.75-2$ $\mathrm{mm}$ de ancho, nectario $0.25-0.5 \mathrm{~mm}$ de largo, conspicuo; ovario 1.5-1.75 mm de largo y ca. $2.5 \mathrm{~mm}$ de ancho, densamente pubescente; pistilo no sobrepasando el tubo estaminal, estilo 5-6 mm de largo, densamente pubescente o pubescente sólo en la base, estigma 0.5-0.6 mm de largo y 1.5-1.8 mm de diámetro. Flores pistiladas desconocidas. Frutos 5-8 cm de largo y 4$5.5 \mathrm{~cm}$ de ancho, piriformes o subglobulosos cuando inmaduros, con numerosas y conspicuas costillas longitudinales (casi como alas), sin lenticelas, densamente ferrugíneo-puberulentos, tetra o pentaloculares, base 
atenuada a obtusa, ápice obtuso a truncado, ginóforo 1-2 mm de largo, pericarpo 2-7 mm de grosor; semillas 2 por lóculo, $1.3-2 \mathrm{~cm}$ de largo, subrodeadas por la sarcotesta.

Distribución. Especie endémica en Costa Rica; se conoce en bosques húmedos de la vertiente caribe en Baja Talamanca, en la vertiente pacífica en Fila Costeña norte (Fila Tinamaste) y Península de OsaGolfito, entre 0 y $900 \mathrm{~m}$.

Fenología. Flores en enero y diciembre; frutos en julio y agosto.

Guarea macrocalyx se distingue entre las especies del género por las flores con cáliz de gran tamaño, bi o trilobado, lóbulos generalmente con tamaño irregular, con una o dos carinas conspicuas y el ápice espinuloso; También se caracteriza por ser un arbusto o arbolito pequeño con foliolos grandes, inflorescencias de apariencia racemosa, flores con la corola y el ovario densamente pubescentes, ovario tetra o pentalocular, lóculos con dos óvulos superpuestos y frutos piriformes o subglobulosos cuando inmaduros, con costillas longitudinales conspicuas, casi como alas.

Esta especie está estrechamente relacionada con la sudamericana $G$. trunciflora C. DC. por las flores grandes y de similar tamaño, cáliz entre 7 y $8 \mathrm{~mm}$ de largo, pétalos entre 11 y $14 \mathrm{~mm}$ de largo y tubo estaminal entre 8.5 y $10 \mathrm{~mm}$ de largo; además, el cáliz muestra dos a cuatro lóbulos irregulares, el lado externo de los pétalos y el ovario son pubescentes y el ovario es tetra o pentalocular, con 2 óvulos superpuestos por lóculo. Esta última se diferencia debido a que tiene tallitos ferrugíneo-tomentosos, hojas con peciólulos más cortos, entre 2 y $4 \mathrm{~mm}$ de largo, con hasta 13 pares de foliolos, envés puberulento, tirsos piramidales laxamente ramificados y cáliz generalmente más pequeño, hasta $8 \mathrm{~mm}$.

Guarea macrocalyx se podría relacionar, también, con la centroamericana $G$. rhopalocarpa Radlk. y con las sudamericanas G. caulobotrys Cuatrec. y G. cristata T.D. Penn., porque las cuatro comparten pétalos y pistilos pubescentes, ovario tetra o pentalocular, lóculos con dos óvulos superpuestos y frutos acostillados. Estas especies se distinguen de G. macrocalyx por las flores con cáliz más pequeño, entre 2.5 y $7 \mathrm{~mm}$, lóbulos regulares, sin carinas y no espinulosos distalmente.

Etimología. El epíteto griego macrocalyx hace alusión al gran cáliz que presenta la especie, que la hace distintiva en el género.
Especímenes examinados. COSTA RICA. Limón: Talamanca, cuenca del Sixaola, San Miguel, 30-100 m, 09॰34'30”N, 8240’00”W, 21 ene 1997 (fl), $J$. González 1711 (INB). Puntarenas: Golfito, Jiménez, Dos Brazos de Río Tigre, Cerro Rincón, 745 m, $08^{\circ} 31^{\prime} 35^{\prime \prime} \mathrm{N}, 83^{\circ} 28^{\prime} 12^{\prime \prime W}, 28$ ago 1990 (fr), G. Herrera 4162 (INB); Osa, Reserva Forestal Golfo Dulce, Aguabuena, después de la fila Casaloma, camino viejo a Sierpe, 350 m, $08^{\circ} 43^{\prime} \mathrm{N}, 83^{\circ} 32^{\prime} \mathrm{W}, 24$ dic 1991 (fl), $R$. Aguilar 790 (INB); Fila Costeña, Río Piedras Blancas, $2 \mathrm{~km}$ al norte, alrededores de Cerro Anguciana, $900 \mathrm{~m}$, 0849'30"N, 83¹1'45'W, 28 jul 1993 (fr), R. Aguilar 2957 (CR, INB); Sierpe, San Juan, siguiendo la fila entre Guerra y San Juan, camino a Cerro Chocuaco, $630 \mathrm{~m}, 08^{\circ} 43^{\prime} 50^{\prime} \mathrm{N}, 83^{\circ} 33^{\prime} 35^{\prime \prime} \mathrm{W}, 26$ ene 1991 (fl), H. Herrera 4876 (INB); Parque Nacional Corcovado,

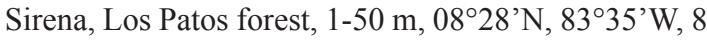
jul 1989 (fr), C. Kernan 1214 (INB).

\section{Guarea montana Al. Rodr., sp. nova}

Per sequentes characteres nova species haec Guarea montana distinguitur: Pecioluli ad basem elongati et incrassati, corola pistilumque pubescentes, ovarium cum duobus per loculum superpositis ovulis, fructus saepe piriformi, non vel leviter costulati, semina duo per loculum.

TIPO: COSTA RICA. Puntarenas; Puntarenas, Cordillera de Tilarán, Reserva Biológica Monteverde, San Luis, Buen Amigo, camino a Veracruz, 1100 m, $10^{\circ} 16^{\prime} 33^{\prime \prime N}, 84^{\circ} 47^{\prime} 45^{\prime}$ 'W, 7 mar 1994 (fl), Z. Fuentes 653 (Holotipo: INB, isotipos: CR, MO). Fig. 8.

Árbol entre 6 y $25 \mathrm{~m}$ de altura. Tallitos esparcidamente puberulentos, en especial las ramitas terminales, con diminutas lenticelas. Hojas pinnadas, con una yema terminal de crecimiento intermitente; pecíolos 2-8 cm de largo, esparcidamente puberulentos, glabrados con la edad, lado adaxial aplanado y con bordes agudos; raquis $3-30 \mathrm{~cm}$ de largo, puberulento, glabrado con la edad, más o menos aplanado y canaliculado adaxialmente, largo entre foliolos $1.5-8 \mathrm{~cm}$; foliolos 1-8 pares, opuestos, peciólulos $0.5-2.5 \mathrm{~cm}$ de largo y $1.5-4 \mathrm{~mm}$ de ancho; lámina $2.5-23 \mathrm{~cm}$ de largo y $1.5-7 \mathrm{~cm}$ de ancho, oblongo-elíptica, oblongoobovada o lanceolada, adaxial y abaxialmente concolora, gris-verdosa o gris-rojiza al secar, haz sin papilas, envés glabrescente, sin glándulas rojizas, base cuneada a obtusa, ápice agudo o cuspidado, nervadura eucamptódroma, 7-14 pares de venas secundarias. Inflorescencias axilares o ramifloras, solitarias, tirsos 
estrechos, en ocasiones pareciendo racimos, 4-24 cm de largo, ramas laterales hasta $8 \mathrm{~cm}$ de largo, multifloras, erectas, pedúnculo hasta $1.5 \mathrm{~cm}$ de largo, a menudo indefinido. Flores con pedicelo $1-4 \mathrm{~mm}$ de largo, articulado, bracteolas 1-2, entre 0.5 y $0.75 \mathrm{~mm}$ de largo. Flores estaminadas con cáliz $2-4.75 \mathrm{~mm}$ de largo, ciatiforme, puberulento, lóbulos 4 , incisos 1/43/4 del tamaño del cáliz; pétalos 4, 12-14 mm de largo y 4-6 mm de ancho, rojo-vino, ápice agudo, lado externo seríceo, interno papilado; tubo estaminal $8-10 \mathrm{~mm}$ de largo y 4-5 $\mathrm{mm}$ de ancho, ápice crenulado, lado externo papilado; anteras $8,1.5-2 \mathrm{~mm}$ de largo y $0.6-0.8$ $\mathrm{mm}$ de ancho; ginóforo glabro, $1.25-2 \mathrm{~mm}$ de largo y $1-1.25 \mathrm{~mm}$ de ancho, nectario $0.55-1.25 \mathrm{~mm}$ de largo, conspicuo; ovario $2.5-3 \mathrm{~mm}$ de largo y $1.75-2 \mathrm{~mm}$ de ancho, diminutamente seríceo; pistilo igual o sobrepasando levemente el tubo estaminal, estilo $4.5-5 \mathrm{~mm}$ de largo, esparcidamente pubescente, estigma $0.3-0.5 \mathrm{~mm}$ de largo y ca. $1.5 \mathrm{~mm}$ de diámetro. Flores pistiladas con cáliz 2.5-3.5 mm de largo, ciatiforme, diminuta y esparcidamente estrigoso, lóbulos 4 , incisos entre $1 / 4$ y 3/4 del tamaño del cáliz; pétalos 4-6, 7-8 mm de largo y 2-3.5 $\mathrm{mm}$ de ancho, rosados a blancos, ápice agudo, lado externo seríceo, interno papilado; tubo estaminal 5.5-6.5 mm de largo y ca. $4 \mathrm{~mm}$ de ancho, ápice crenado, lado externo papilado; anteroides 8-10, 0.9-1.2 $\mathrm{mm}$ de largo; ginóforo glabro, 0.5-0.75 $\mathrm{mm}$ de largo y $1.3 \mathrm{~mm}$ de ancho, nectario $0.4-0.7 \mathrm{~mm}$ de largo, conspicuo; ovario tetra o pentalocular, seríceo, $c a .3 \mathrm{~mm}$ de largo y $2.5 \mathrm{~mm}$ de ancho, con 2 óvulos superpuestos por lóculo; pistilo subigual o sobrepasando levemente el tubo estaminal, estilo seríceo, $1.75-2.5 \mathrm{~mm}$ de largo, estigma ca. $0.3 \mathrm{~mm}$ de largo y $1.5 \mathrm{~mm}$ de ancho. Frutos 4-6 cm de largo y $2.5-4.5 \mathrm{~cm}$ de ancho, piriformes a raro subglobulosos, no acostillados o con numerosas e inconspicuas costillas, no lenticelados, base atenuada, menos frecuente obtusa, ápice obtuso, rojizos al madurar, puberulentos, tetraloculares, ginóforo $1.5-2 \mathrm{~mm}$ de largo, pericarpo 6-20 mm de grosor; semillas 2 por lóculo, $1.5-2 \mathrm{~cm}$ de largo, subrodeadas por la sarcotesta.

Distribución. Endémica en Costa Rica; habita en bosques pluviales de ambas vertientes de las cordilleras de Guanacaste y Tilarán, así como en la vertiente pacífica de la Cordillera de Talamanca (San Vito), entre 550 y $1580 \mathrm{~m}$.

Fenología. Flores entre enero y junio, además en diciembre; frutos entre enero y junio, también entre setiembre y diciembre.

Guarea montana se reconoce por la combinación de los siguientes caracteres: flores con corola y pistilo pubescentes, ovario tetra o pentalocular, lóculos con dos óvulos superpuestos, frutos generalmente piriformes, nada o levemente acostillados, con pericarpo grueso, dos semillas por lóculo y foliolos con peciólulos alargados y engrosados en la base; además, se caracteriza por el hábito arborescente, inflorescencias estrechas y distribución geográfica en cordilleras.

Esta especie se podría relacionar con G. cartaguenya Cuatrec., G. grandifolia C. DC. y G. rhopalocarpa Radlk. por las flores con pétalos y pistilo pubescentes, lóculos con dos óvulos superpuestos, frutos piriformes, grandes, alcanzando más de $4 \mathrm{~cm}$ de largo, partes vegetativas puberulentas o glabrescentes y foliolos con nervadura eucamptódroma. Guarea cartaguenya y $G$. grandifolia se diferencian debido a que los peciólulos son más cortos, entre 0.4 y $1 \mathrm{~cm}$, y las inflorescencias llegan a ser más grandes, hasta $50 \mathrm{~cm}$ de largo, con ramas laterales hasta $26 \mathrm{~cm}$ de largo; además, la primera tiene pétalos más grandes, hasta $17.5 \mathrm{~mm}$ de largo, y el envés de los foliolos crispadopuberulento, mientras que la segunda presenta hojas con mayor número de foliolos, hasta 17 pares, raquis más largo, hasta $110 \mathrm{~cm}$ y frutos con el pericarpo más delgado, entre 3.5 y $7 \mathrm{~mm}$. Guarea rhopalocarpa es diferente a $G$. montana por tener estipelas en el ápice de los pecíolos (frecuentemente caedizas en especímenes de herbario), papilas en el haz de los foliolos, inflorescencias estrictamente racemosas, flores masculinas con pétalos más estrechos, entre 2 y $2.5 \mathrm{~mm}$, frutos a menudo caulifloros, en la mayoría de los casos más acostillados, pericarpo generalmente más delgado, entre 4 y $9 \mathrm{~mm}$, y generalmente es una especie de menor tamaño, entre 2 y $12 \mathrm{~m}$ de altura. $G$. montana se conoce con el nombre popular de zapote [de] mico.

Etimología. Esta especie habita en zonas montañosas; a esto se refiere el epíteto latino montana.

Especímenes examinados. COSTA RICA. Alajuela: Monteverde, Río Peñas Blancas, Quebrada Celeste, 850 m, $10^{\circ} 20^{\prime} \mathrm{N}, 84^{\circ} 42^{\prime} \mathrm{W}, 12$ sept 1989 (fr), E. Bello 1252 (INB); upper drainage of the Río Peñas Blancas below the Monteverde Cloud Forest Nature Reserve, 1250-1350 m, 09 $17^{\prime} \mathrm{N}, 84^{\circ} 86^{\prime} \mathrm{W}, 26$ febr 1977 (fr), W. Burger 10786 (CR); 1500 m, 1 May 1975 (fr), L.R. Holdridge 6832 (CR); Upala, Parque Nacional Guanacaste, Sector San Ramón, 550 m, 1052'50’N, 85²4'05'W, 30 ene 1995 (fr), U. Chavarría 1198 (CR); de Nueva Zelandia $1 \mathrm{~km}$ antes de Finca San Cristóbal, $550 \mathrm{~m}, 10^{\circ} 52^{\prime} 50^{\prime} \mathrm{N}, 8^{\circ} 24^{\prime} 05^{\prime} \mathrm{W}, 11$ nov 
1994 (fr), R. Espinoza et al. 1185 (INB). Guanacaste: Liberia, Parque Nacional Guanacaste, Estación Cacao, $1100 \mathrm{~m}, 10^{\circ} 55^{\prime} 45^{\prime \prime} \mathrm{N} 85^{\circ} 28^{\prime} 15^{\prime \prime} \mathrm{W}, 3$ jun 1990 (fr), E. Alcázar 45 (CR, INB); loc. cit., sendero a la cima, $1100 \mathrm{~m}, 10^{\circ} 55^{\prime} 33^{\prime \prime} \mathrm{N}, 8^{\circ} 28^{\prime} 06^{\prime \prime} \mathrm{W}, 18$ mar 1998 (fl), A. Rodríguez et al. 3123 (INB); sendero Nayo, $1100 \mathrm{~m}$, $10^{\circ} 55^{\prime} 43^{\prime}$ 'N, $85^{\circ} 28^{\prime} 10^{\prime \prime} \mathrm{W}, 9$ febr 1995 (fr), E. Alfaro 57 (INB); west flank of Volcán Cacao, $10^{\circ} 55^{\prime} 32^{\prime}$ N , 85²8'02”'W, 21 jun 1994 (fr), W. Alverson 2804 (CR); trail to Cacao summit, $c a .1 \mathrm{~km}$ from station, 1300 m, $10^{\circ} 55^{\prime} 48^{\prime \prime} \mathrm{N}, 85^{\circ} 27^{\prime} 52^{\prime \prime} \mathrm{W}, 15$ mar 2003, B. Boyle 7158 (INB); $1100 \mathrm{~m}, 10^{\circ} 55^{\prime} 45^{\prime \prime} \mathrm{N}, 85^{\circ} 28^{\prime} 15^{\prime \prime} \mathrm{W}, 17 \mathrm{dic}$ 1990 (fr), C. Chávez 487 (INB); 1100 m, 1055’38”N, 85²9'38”'W, 3 jun 1990 (fr), R. Delgado 21 (INB); Sendero Arenal, $1100 \mathrm{~m}, 10^{\circ} 55^{\prime} 43^{\prime \prime} \mathrm{N}, 8^{\circ} 28^{\prime} 10^{\prime \prime} \mathrm{W}$, 9 febr 1995 (fl), B. Gamboa 55 (INB); Cerro Cacao, $1100 \mathrm{~m}, 10^{\circ} 55^{\prime} 43^{\prime} \mathrm{N}, 85^{\circ} 28^{\prime} 10^{\prime} \mathrm{W}, 8$ febr 1995 (fr), $R$. Villalobos 41 (INB); Sector San Ramón, 550 m, $10^{\circ} 52^{\prime} 50^{\prime \prime} \mathrm{N}, 8^{\circ} 24^{\prime} 05^{\prime} \mathrm{W}, 30$ ene 1995 (fr), $U$. Chavarría 1198 (INB); Volcán Miravalles, $800 \mathrm{~m}$, $10^{\circ} 42^{\prime} \mathrm{N} 85^{\circ} 07^{\prime} \mathrm{W}, 8$ abr 1973 (fl), W. Burger 9113 (CR, DUKE,); three km N Santa Elena, Atlantic exposure near continental divide on Bello farm, 1500 m, $10^{\circ} 20^{\prime} \mathrm{N}, 84^{\circ} 50^{\prime} \mathrm{W}, 20$ dic 1985 (fr), W. Haber 3809 (CR); Hacienda Santa María, 800-900 m, $10^{\circ} 48^{\prime} \mathrm{N}$, $85^{\circ} 49^{\prime} \mathrm{W}, 15$ oct 1987 (fr), G. Herrera 867 (CR); Parque Rincón de la Vieja, del Mirador siguiendo la Fila al Volcán Santa María, $1100-1200$ m, $10^{\circ} 46^{\prime} \mathrm{N}$, 8549’W, 25 nov 1987 (fr), G. Herrera 1397 (CR). Puntarenas: Monteverde, en potrero, 1520-1580 m, 11 ene 1977 (fr), V.J. Dryer 1114 (CR); en cafetal del Valle San Luis, 1100-1150 m, 22 febr 1977 (fl), V.J. Dryer 1209 (CR); en potrero cerca de la Reserva, 15201560 m, 5 abr 1977 (fr), V.J. Dryer 1293 (CR, MO); en potreros, 1520-1560 m, 5 abr 1977 (fl), V.J. Dryer 1328 (CR, MO); 1500-1560 m, 22 May 1977 (fl), V.J. Dryer 1367 (CR); San Luis, Finca Buen Amigo, 1100 m, 10¹6’30”N, 8449'30"W, 23 mar 1993 (fl), $Z$. Fuentes 267 (INB); private land to West side of road to reserve, $1420 \mathrm{~m}, 10^{\circ} 18^{\prime} \mathrm{N}, 84^{\circ} 48^{\prime} \mathrm{W}, 10$ jun 1985 (fl), M. H. Grayum 5401 (CR); along Río Guacimal in community Female, 1350 m, 20 abr 1979 (fl), $W$. Haber 315 (CR); forest patches and pastures, $1400 \mathrm{~m}$, $10^{\circ} 20^{\prime} \mathrm{N}, 84^{\circ} 50^{\prime} \mathrm{W}, 30 \mathrm{Dec} 1985$ (fl), W. Haber 4028 (CR); $1400 \mathrm{~m}, 10^{\circ} 20^{\prime} \mathrm{N}, 84^{\circ} 50^{\prime} \mathrm{W}, 15$ May 1986 (fl), W. Haber 4932 (CR); 1500 m, 1 May 1975 (fl), L.R. Holdridge 6832 (CR); Monteverde cloud forest and adjacent pasture lands, 1500 m, 19 May 1973 (fl), J.L. Luteyn 3672 (DUKE); San Vito, Concepción de Agua Vita, 1200 m, 2 mar 1978 (fl), T.D. Pennington 10146 (CR); Biological Reserve, 1500 m, 2 jun 1978 (fr), T.D. Pennington 10153 (CR); pasture and forest remnants below Figueroas land, 1250 m, 26 ene 1984 (fr), T.D. Pennington 11439 (CR).

\section{Guarea pilosa Al. Rodr., sp. nova}

Frutex vel arbor parva, partes infertiles valde pubescentes, inflorescentiae pauciflorae, petali sparse pubescentes, ovarium sericeum, ovulum unum per loculum, fructus globulosi, semen unum per loculum; characteres praecedentes hanc novam speciem generis Guareae dignoscent.

TIPO: COSTA RICA. Alajuela; Parque Nacional Rincón de la Vieja, Río Jala Piedras, $3 \mathrm{~km}$ aguas abajo de la carretera, falda norte del Volcán Santa María, $500 \mathrm{~m}$, $10^{\circ} 50^{\prime} 21^{\prime \prime} \mathrm{N}, 85^{\circ} 16^{\prime} 04^{\prime \prime} \mathrm{W}, 14$ febr 1991 (fr), G. Rivera 1098 (Holotipo: INB, isotipos: CR, MO). Fig. 9.

Arbusto o arbolito de 2 a $7 \mathrm{~m}$ de altura. Tallitos densamente pardo-hirsútulos, al menos en ramitas terminales, aunque hirsutos o pilosos en plantas juveniles, con o sin lenticelas esparcidas. Hojas pinnadas, con una yema terminal de crecimiento intermitente; pecíolos $1.5-7 \mathrm{~cm}$ de largo, pilosos o puberulentos, glabrescentes con la edad, subteretes, lado adaxial levemente aplanado y con bordes apenas agudos; raquis 2-70 $\mathrm{cm}$ de largo, piloso o puberulento, glabrescente con la edad, subcuadrado y levemente canaliculado en el lado adaxial, largo entre foliolos 2-10 $\mathrm{cm}$; foliolos 1-8 pares, opuestos, peciólulos $0.3-1 \mathrm{~cm}$ de largo y 1-4 mm de ancho; lámina $1.5-29 \mathrm{~cm}$ de largo y 1-13 cm de ancho, elíptica a obovado-elíptica, adaxial y abaxialmente concolora, verde-grisácea al secar, haz sin papilas, envés esparcida a densamente pubescente, incluso en el margen del foliolo, sin glándulas rojizas, base cuneada a obtusa, ápice cuspidado a cortoacuminado, nervadura eucamptódroma, 9-20 pares de venas secundarias. Inflorescencias axilares o caulifloras, solitarias, racemosas, $c a .5 \mathrm{~cm}$ de largo, paucifloras, erectas, pedúnculo generalmente indefinido. Flores subsésiles o pedicelos hasta $2 \mathrm{~mm}$ de largo, articuladas, con un par de bracteolas entre 0.75 y $2 \mathrm{~mm}$ de largo. Flores estaminadas con cáliz 1-1.5 mm de largo, pateliforme, esparcidamente pubescente, lóbulos 4 , incisos 1/5 del tamaño del cáliz; pétalos (4-)5, ca. 7 $\mathrm{mm}$ de largo y $1.5 \mathrm{~mm}$ de ancho, ápice agudo, lado externo esparcidamente pubescente, interno papilado; tubo estaminal $c a .5 .5 \mathrm{~mm}$ de largo, ápice crenulado, lado externo papilado; anteras 7, ca. $0.6 \mathrm{~mm}$ de largo; ginóforo glabro, $c a .0 .6 \mathrm{~mm}$ de largo, nectario 0.3-0.5 $\mathrm{mm}$ de largo, conspicuo; ovario seríceo, $c a .1 .25 \mathrm{~mm}$ de largo y $1 \mathrm{~mm}$ de ancho; pistilo igual o sobrepasando levemente el tubo estaminal, estilo ca. $2 \mathrm{~mm}$ de largo, glabro. Flores pistiladas no observadas. Frutos $c a$. $1.5 \mathrm{~cm}$ de largo y $1.5 \mathrm{~cm}$ de ancho, globulosos, no 
acostillados, base obtusa, ápice obtuso a subtruncado, rojizos al madurar, esparcidamente pubescentes a glabrescentes con la edad, tetraloculares, ginóforo $c a$. $2 \mathrm{~mm}$ de largo, pericarpo 1-1.5 mm de grosor; semillas 1 por lóculo, $c a .1 \mathrm{~cm}$ de largo, subrodeada por la sarcotesta.

Distribución. Costa Rica y Nicaragua. Se conoce en bosques húmedos y pluviales de la vertiente caribe de Nicaragua, en la cuenca del Río San Juan; en Costa Rica en las llanuras de San Carlos y de Tortuguero y en las cordilleras de Guanacaste, Tilarán, Central y Talamanca, entre 30 y $1300 \mathrm{~m}$.

Fenología. Flores en febrero y diciembre; frutos entre enero y marzo y en mayo, agosto y diciembre.

Guarea pilosa se reconoce por la combinación de los siguientes caracteres: arbusto o árbol pequeño, partes vegetativas, incluyendo el envés y el margen de los foliolos, densamente pubescentes, al menos en ramitas terminales, hasta ocho pares de foliolos, inflorescencias paucifloras, flores con pétalos esparcidamente pubescentes, ovario seríceo con un óvulo por lóculo y frutos globulosos, con pubescencia esparcida cuando inmaduros, glabrados con la edad, con una semilla por lóculo.

Esta especie está estrechamente relacionada con Guarea bullata Radlk., G. chiricana Standl., G. donnell-smithiii C. DC. y G. petensis Coronado ined., debido a la pubescencia de partes vegetativas, forma y tamaño de foliolos, ausencia de papilas en el haz y de glándulas rojizas en el envés de las hojas, tamaño de los pétalos, entre 5 y $7 \mathrm{~mm}$, y ovario pubescente, con frecuencia tetralocular y con un óvulo por lóculo. Estas especies se distinguen debido a que son árboles que a menudo alcanzan mayor altura, entre 2 y $20 \mathrm{~m}$, las partes vegetativas generalmente son menos pubescentes (excepto G. donnell-smithii) y las inflorescencias (tirsos, panículas o racimos) son regularmente multifloras y más largas, entre 2 y 12 $\mathrm{cm}$ de largo. Además, G. bullata es distintiva debido a que presenta hojas con mayor número de foliolos, hasta 24 pares, con frecuencia abollados, y los frutos tienen el pericarpo más grueso, entre 3 y $7 \mathrm{~mm}$. En G. chiricana y $G$. petenensis la lámina foliar es más pequeña, hasta $18 \mathrm{~cm}$ de largo y $7 \mathrm{~cm}$ de ancho, los pétalos son glabros y el ovario es apenas pubescente. En G. chiricana los frutos a menudo son atenuados hacia la base. Guarea donnell-smithii, una especie restringida a la vertiente pacífica de Costa Rica, se caracteriza por mostrar peciólulos más cortos, entre
0.1 y $0.3 \mathrm{~cm}$, inflorescencias ordinariamente más grandes, laxas y multifloras, entre 2 y $12 \mathrm{~cm}$ de largo, pétalos púrpura y con frecuencia densamente pubescentes.

Etimología. El epíteto latino pilosa hace alusión a la pubescencia presente en las partes vegetativas de la planta.

Especímenes examinados. NiCARAGUA. Río San Juan: $1 \mathrm{~km}$ al E del Río Sábalos, $100 \mathrm{~m}, 11^{\circ} 02^{\prime} \mathrm{N}$, $84^{\circ} 27^{\prime} \mathrm{W}, 21$ febr 1984 (fr), P.P. Moreno 23184 (MO); Quebrada Santa Crucita, $50 \mathrm{~m}, 11^{\circ} 02^{\prime} \mathrm{N}, 84^{\circ} 25^{\prime} \mathrm{W}$, 27 febr 1984 (fr), P.P. Moreno 23433 (MO); El Castillo, Reserva Indio-Maíz, Cerro El Diablo, 100 m, $11^{\circ} 01^{\prime} \mathrm{N}, 84^{\circ} 12^{\prime} \mathrm{W}, 10$ dic 1998 (fr), R. Rueda 9698 (INB). COSTA RICA. Alajuela: Reserva Biológica Monteverde, Río Peñas Blancas, 700-800 m, $10^{\circ} 21^{\prime} \mathrm{N}, 84^{\circ} 40^{\prime} \mathrm{W}, 26$ mar 1990 (fr), E. Bello 2065 (INB); $900 \mathrm{~m}, 10^{\circ} 19^{\prime} \mathrm{N}, 8^{\circ} 44^{\prime} \mathrm{W}, 12$ May 1987 (fr), W. Haber 7102 (MO); San Carlos, Pital, Boca Tapada, Finca Daniel Murillo, parcela permanente 9,

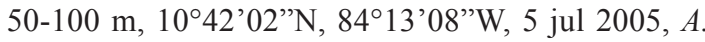
Rodríguez 9645 (INB); San Ramón, Ángeles, Bajo Rodríguez, entrando por Santa Rita, cuenca del Río Balsa, alrededores del río, $250-300 \mathrm{~m}, 10^{\circ} 17^{\prime} 50^{\prime \prime} \mathrm{N}$, 84³1'40"W, 29 abr 2004, A. Rodríguez 9572 (INB); Golfito, Finca Virgilio Mena, 30-50 m, 10 50 '08'N, 85³4'29”'W, 5 mar 2005 (fr), D. Solano 1994 (INB); Guanacaste: La Cruz, Área de Conservación Guanacaste, Estación Pitilla, 700 m, 1059'26”N, $85^{\circ} 25^{\prime} 40^{\prime \prime} \mathrm{W}, 11$ sept 1990, C. Moraga 59 (INB, MO); Heredia: Sarapiquí, La Virgen, Estación Biológica La Selva, the OTS Field Station on the Río Puerto Viejo just $\mathrm{E}$ of its junction with the Río Sarapiquí, 2 mar 1981 (fr), J. Folsom 9163 (DUKE); at confluence of Río Sarapiquí and Río Puerto Viejo, Atlantic slope, $50-75 \mathrm{~m}, 10^{\circ} 26^{\prime} \mathrm{N}, 8^{\circ} 01^{\prime} \mathrm{W}, 28$ ene 1989 (fr), M.H. Grayum 9307 (DUKE, MO); senderos aledaños a la estación, $100 \mathrm{~m}, 10^{\circ} 26^{\prime} 00^{\prime} \mathrm{N}, 84^{\circ} 00^{\prime} 30^{\prime \prime} \mathrm{W}, 4$ febr 2004 (fr), A. Rodríguez 8389 (INB); A. Rodríguez 8391 (INB); Parque Nacional Braulio CarrilloEstación Carrillo, antigua propiedad Chacón, $450 \mathrm{~m}$ 10 febr 1984 (fr), L.D. Gómez et al. 20969 (MO). Limón: N flank of Fila Matama, in headwaters Río

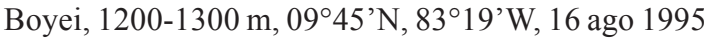
(fr), M.H. Grayum 11013 (INB); between Siquirres and the Río Pacuare, and remnant forest on steep hill south of the railroad bridge over the Río Pacuare, 50$100 \mathrm{~m}, 10^{\circ} 05^{\prime} \mathrm{N}, 8^{\circ} 29^{\prime} \mathrm{W}, 20-22$ dic 1969 (fl), $W$. Burger \& R. Liesner 7003 (MO). 


\section{Guarea tafae-malekui Al. Rodr., sp. nova}

Distinguo hanc novam speciem quia est unica, a omnibus speciebus generis Guareae, cum tribus vel quattuor superpositis ovulis per ovarii loculum.

TIPo: COSTA RICA. Alajuela; San Carlos, Parque Nacional Arenal, cuenca del San Carlos, Cerro Chato, sendero que lleva a la laguna, $1000 \mathrm{~m}, 10^{\circ} 26^{\prime} 30^{\prime \prime} \mathrm{N}$, 8441'28'W, 22 ago 2000 (fl, fr), A. Rodríguez 6238 (Holotipo: INB, isotipos: CR, MO). Fig. 10.

Árbol o arbusto entre 3 y $6 \mathrm{~m}$ de altura, cortamente ramificado, dioico. Tronco con corteza interna blancocrema; tallitos pardo-puberulentos, principalmente en ramitas terminales, con lenticelas esparcidas. Hojas pinnadas, con una yema terminal de crecimiento intermitente, aunque a menudo tempranamente decidua; pecíolos 10-25 cm de largo, puberulentos, lado adaxial aplanado y con bordes agudos; raquis 5-55 cm de largo, puberulento, subcuadrado, adaxialmente aplanado, largo entre foliolos $1-8 \mathrm{~cm}$; foliolos 1-8 pares, opuestos, peciólulos $0.5-1.5 \mathrm{~cm}$ de largo y $1.5-$ $5 \mathrm{~mm}$ de ancho; lámina 4-45 cm de largo y 3.5-14 $\mathrm{cm}$ de ancho, oblongo-elíptica a oblongo-obovada, adaxial y abaxialmente concolora, verde-grisácea al secar, haz en ocasiones diminutamente papilado en el nervio principal, envés glabrescente, sin glándulas, base cuneada a obtusa, ápice acuminado o cuspidado, nervadura eucamptódroma, 6-18 pares de venas secundarias. Inflorescencias axilares o infrafoliares, solitarias, panículas estrechas, $8-15 \mathrm{~cm}$ de largo, ramas laterales hasta $3 \mathrm{~cm}$ de largo, generalmente paucifloras, erectas o péndulas, pedúnculo $c a .1 \mathrm{~cm}$ de largo. Flores subsésiles o con pedicelo hasta $5 \mathrm{~mm}$ de largo, articulado, con 3 ó 4 bracteolas entre 3 y $10 \mathrm{~mm}$ de largo. Flores estaminadas con cáliz 8-10 mm de largo, ciatiforme, densamente puberulento, lóbulos 4 , incisos entre $1 / 5$ y 3/4 del tamaño del cáliz; pétalos 4 , 15-17 $\mathrm{mm}$ de largo y 8-10 $\mathrm{mm}$ de ancho, ápice agudo, lado externo seríceo, interno papilado; tubo estaminal 14$16 \mathrm{~mm}$ de largo y 7-9 mm de ancho, ápice denticulado, lado externo papilado; anteras 8-9, ca. $3 \mathrm{~mm}$ de largo y 1-1.25 mm de ancho; ginóforo glabro, 1-1.25 mm de largo y 4-4.5 $\mathrm{mm}$ de ancho, nectario 1-1.25 mm de largo, conspicuo; ovario con 6 a 8 lóculos, (3-)4 óvulos por lóculo, 4.5-5 $\mathrm{mm}$ de largo y 5-5.5 $\mathrm{mm}$ de ancho, densa y diminutamente seríceo. Pistilo igual o levemente más pequeño que el tubo estaminal, diminutamente seríceo, estilo 5-6 $\mathrm{mm}$ de largo, seríceo, estigma $0.75-1 \mathrm{~mm}$ de largo y 3-3.5 $\mathrm{mm}$ de ancho. Flores pistiladas desconocidas. Frutos 3-6.5 cm de largo y 3-7.5 cm de ancho, globulosos a globulosopiriformes, no acostillados, sin lenticelas, base obtusa, ápice obtuso a subtruncado, café-rojizos al madurar, densamente pardos a ferrugíneo-puberulentos, en ocasiones glabrescentes con la edad, con 7 u 8 lóculos, ginóforo (1-)3.5-4.5 $\mathrm{mm}$ de largo, pericarpo 3-9 $\mathrm{mm}$ de grosor; semillas 1-4 por lóculo, 0.5-1.6 cm de largo, subrodeadas por la sarcotesta.

Distribución. Especie rara, endémica en Costa Rica; sólo se conocen pocos especímenes de bosques húmedos y pluviales de la vertiente caribe de la Cordillera de Tilarán, en los alrededores del Volcán Arenal, entre 400 y $1000 \mathrm{~m}$.

Fenología. Flores en febrero y agosto; frutos en enero, febrero, abril, mayo, agosto y noviembre.

Guarea tafae-malekui se reconoce por ser la única especie en el género que presenta ovario con tres o cuatro óvulos superpuestos por lóculo; además, se caracteriza por ser un arbusto o arbolito pequeño, cortamente ramificado, hojas con largos pecíolos, foliolos grandes, flores con pétalos, ovario y estilo densamente puberulentos, pétalos largos y muy anchos, nectario muy conspicuo y frutos globulosos a globuloso-piriformes, no acostillados, puberulentos, duros y con una a cuatro semillas por lóculo.

Ovarios con tres o cuatro óvulos biseriados por lóculo es un carácter nunca antes descrito en Guarea; por tanto, define a G. tafae-malekui como una especie disímil y distintiva del género. A pesar de esta significativa diferencia, otros caracteres de la nueva especie son consecuentes y satisfactorios dentro de Guarea; entre éstos tenemos hojas con una yema terminal de crecimiento intermitente (aunque a menudo ausente en hojas viejas), flores con sépalos unidos formando un cáliz ciatiforme, con lóbulos no imbricados, pétalos libres, estambres con filamentos unidos formando un tubo estaminal subcilíndrico, no constricto, anteras insertas en el tubo estaminal, con un conspicuo nectario anular y sobre un ginóforo definido, estigma discoide y frutos capsulares, con las semillas no aladas y subrodeadas por una sarcotesta leñosa.

En Meliaceae, Carapa Aubl., del Nuevo y del Viejo Mundo, y Xylocarpus J. König, del Viejo Mundo, son géneros que presentan ovario con más de dos óvulos biseriados por lóculo, entre (dos-) tres y ocho. Otros géneros meliáceos con más de dos óvulos biseriados por lóculo se diferencian debido a que tienen las semillas aladas. G. tafae-malekui se distingue de Carapa y Xylocarpus debido a que en ambos géneros las hojas 
carecen de yema terminal de crecimiento intermitente y las flores no presentan ginóforo. Además, Carapa posee sépalos imbricados, el ovario tiene entre (dos-) tres y ocho óvulos por lóculo, mientras que Xylocarpus se diferencia por las semillas con la sacotesta corchosa y el hábitat característicamente costero.

Con frecuencia, los especímenes de herbario de Guarea tafae-malekui han sido identificados erróneamente como G. grandifolia; sin embargo, esta especie se diferencia debido a que llega a ser un árbol más grande, hasta $25 \mathrm{~m}$ de altura, con mayor número de foliolos, hasta 17 pares, el raquis es conspicuamente más largo, hasta $110 \mathrm{~cm}$, y los pecíolos evidentemente son más pequeños, hasta $12 \mathrm{~cm}$ de largo, las inflorescencias son más grandes, hasta $50 \mathrm{~cm}$ de largo y $10 \mathrm{~cm}$ de ancho, las flores tienen ovario con dos óvulos por lóculo y los frutos poseen solamente dos semillas por lóculo. También se puede comparar con G. macrocalyx Al. Rodr. (ver comentarios y discusión de esta última).

Las hormigas Myrmelachista flavoguarea Longino (Formicinae, Formicidae) utilizan los tallitos huecos de Guarea tafae-malekui como albergue. Esta nueva especie de hormigas, recientemente descubierta, parece ser específica de esta planta (Longino 2006).

Etimología. El epíteto tafae-malekui fue asignado en memoria de Wilson Morera, quien fue líder sobresaliente de la comunidad indígena maleku de las llanuras de San Carlos, Costa Rica, zona aledaña al área de distribución natural de la especie. Tafa, como era conocido por su pueblo y que en maleku significa el espíritu del jaguar, luchó por mantener la cultura de su pueblo, sobresalió por el amor a su tierra, el respeto que engendraba y la sabia paciencia con que caminaba. Tafa fue llamado a la presencia de sus ancestros en abril del 2005.

Material examinado. COSTA RICA. Alajuela: San Carlos, Arenal Volcano, 19 abr 1990 (fr), Funk 10772 (CR); Finca El Jilguero, $800 \mathrm{~m}, 10^{\circ} 25^{\prime} 25^{\prime \prime} \mathrm{N}$, 84²' $05^{\prime}$ 'W, 29 nov 1992 (fr), G. Herrera 5692 (CR); falda norte del Volcán Arenal, camino a Tabacón, 500600 m, 10²9'40”'N, 8443'20”'W, 18 ene 1994 (fr), Q. Jiménez 1458 (INB); north side of Volcán Arenal, $700 \mathrm{~m}, 10^{\circ} 29^{\prime} \mathrm{N}, 84^{\circ} 41^{\prime} \mathrm{W}, 20$ abr 1973 (fr), R. Lent et al. 3333 (CR, DUKE); Arenal Mundo Aventura, $400 \mathrm{~m}, 10^{\circ} 27^{\prime} 10^{\prime \prime} \mathrm{N}, 84^{\circ} 39^{\prime} 30^{\prime} \mathrm{W}, 17$ febr 2006 (fl), A. Rodríguez 9949 (INB), 17 febr 2006 (fl), 17 febr 2006 (fr), A. Rodríguez 9950 (INB), 17 febr 2006 (fl), A. Rodríguez 9951 (INB), 17 febr 2006 (fl), A. Rodríguez 9952 (INB), 17 febr 2006 (fl), A. Rodríguez 9953 (INB). Guanacaste, six km North of village of Río Chiquito, slope above Lake Arenal, 600-700 m, $10^{\circ} 25^{\prime} \mathrm{N}, 84^{\circ} 46^{\prime} \mathrm{W}, 8$ May 1986 (fr), B. Haber 4825 (CR); Tilarán, camino entre El Silencio y Río Chiquito, 875 m, 10²8’30”N, 8453'15”W, 9 nov 1994 (fr), G. Herrera 7392 (CR).

Agradecimientos. El autor desea agradecer a Claudia Aragón y a Silvia Troyo por el aporte de tan magníficas ilustraciones, a Eduardo Lépiz, Luis Acosta y Luis Diego Vargas por apoyar la recolecta de material botánico en el campo, a Michael Grayum por sus aportes y comentarios y a Carlos O. Morales por su indispensable ayuda en la diagnosis latina de cada especie.

\section{LiTERATURA CITADA}

Coronado, I.M. 2003. Systematic revision and multivariate analysis of the Guarea glabra Vahl (Meliaceae) complex from Mexico to Panama. Thesis for Master of Science degree. University of Saint Louis, Missouri. 157 p.

De Candolle, C. 1878. Meliacées. Monogr. Phan. 1: 399-758.

Longino, J.T. 2006. A taxonomic review of the genus Myrmelachista (Hymenoptera: Formicidae) in Costa Rica. Zootaxa 1141:1-54.

Museo Nacional de Costa Rica. 2006. Base de datos del Herbario Nacional de Costa Rica. San José.

Pennington, T.D. \& B.T. Styles. 1975. A generic monograph of the Meliaceae. Blumea 22(3): 419540 .

\& B.T. Styles. 2001. Meliaceae. In: Stevens, W.D., C. Ulloa, A. Pool \& O. Montiel (eds.). Flora de Nicaragua. Tomo II. Monogr. Syst. Bot. Missouri Bot. Gard. 85: 1419-1430.

Pennington, T.D. 1981. A Monograph of Neotropical Meliaceae. Fl. Neotrop. Monogr. 28: 1-470.

Smith, C.E. 1965. Meliaceae. Flora of Panama. Ann. Missouri Bot. Gard. 52: 55-79.

Standley, P.C. \& J.A. Steyermark. 1946. Meliaceae. Flora of Guatemala, part V. Fieldiana, Bot. 24: 444-468.

\section{REFERENCIA DE INTERNET}

ATTA-INBio. 2006. Base de Datos Atta, Instituto Nacional de Biodiversidad (INBio). http//atta.inbio. ac.cr/ (consultada el 24 de febrero del 2006). 


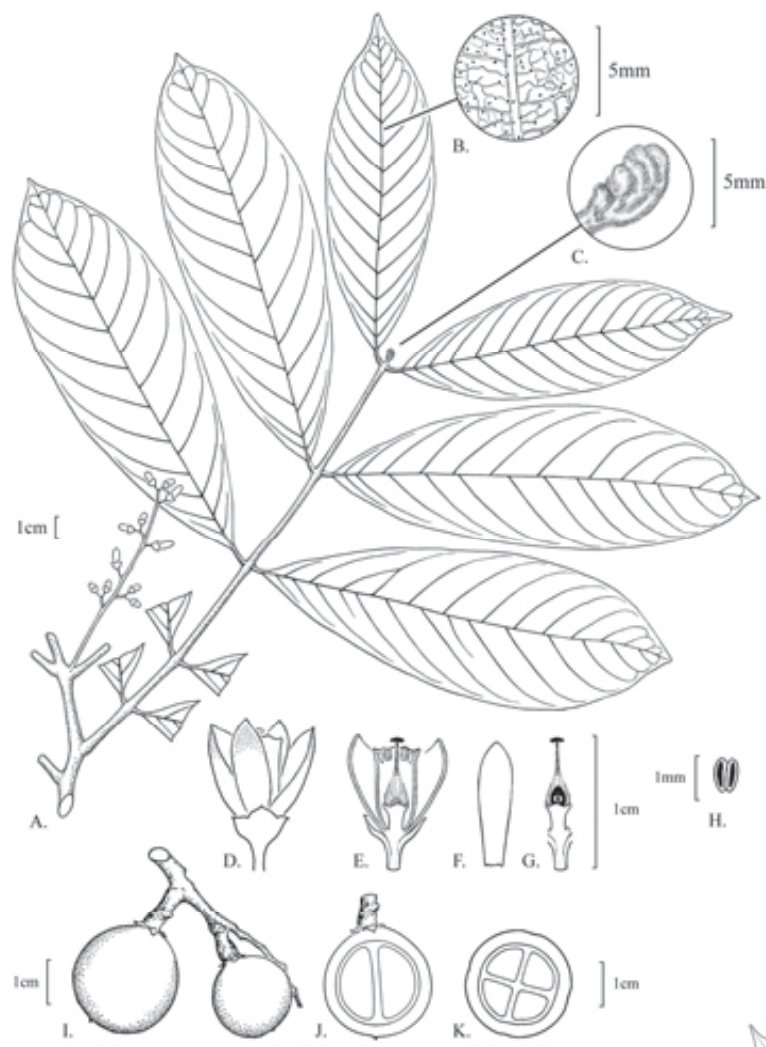

Fig. 1. Guarea adenophylla Al. Rodr. (W. Haber 10791, INB).

A. Hábito.

B. Glándulas en el envés de la hoja.

C. Yema terminal de la hoja.

D. Flor masculina.

E. Corte longitudinal de flor masculina.

F. Pétalo de flor masculina.

G. Corte longitudinal de ovario de flor masculina.

H. Antera.

I. Frutos.

J. Corte longitudinal de fruto.

K. Corte transversal de fruto.

Fig. 2. Guarea aguilarii Al. Rodr. (C. Kernan \& P. Phillips 1020, INB).

A. Hábito.

B. Yema terminal de la hoja.

C. Corte transversal de fruto.

D. Corte longitudinal de fruto.

E. Fruto.

F. Inflorescencia femenina.

G. Flor femenina.

H. Corte longitudinal de flor femenina.

I. Pétalo de flor femenina.

J. Botón de flor femenina.

K. Corte transversal de ovario de flor femenina.

L. Anteroide.

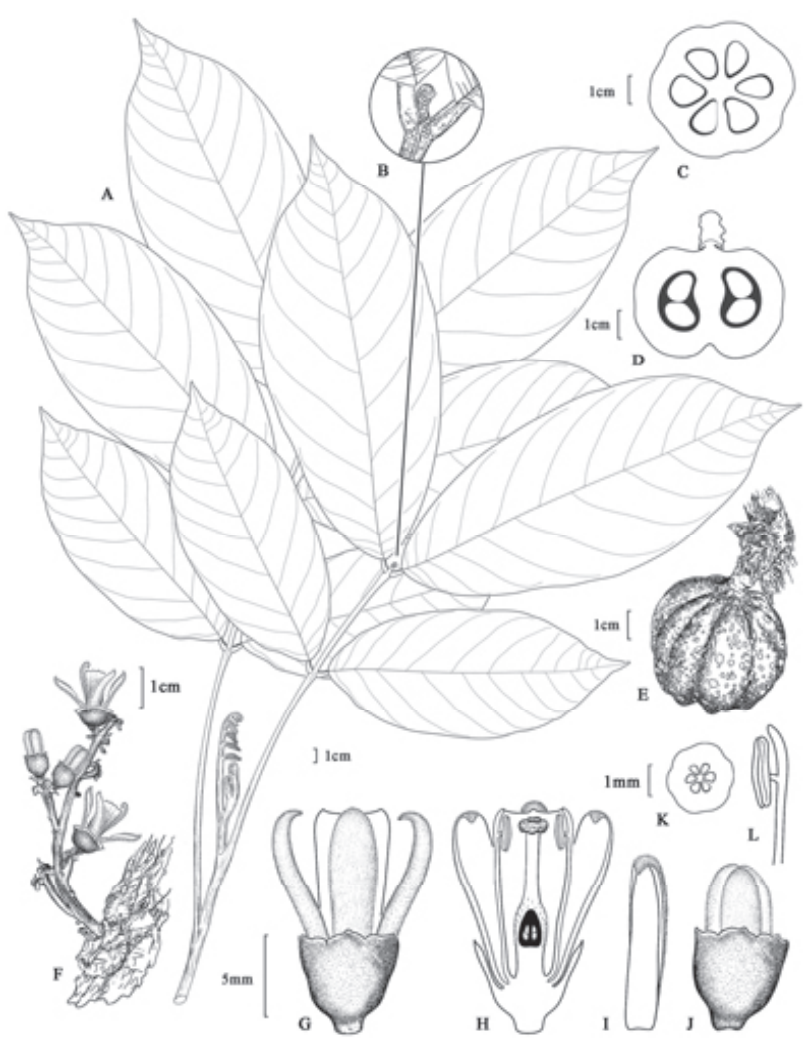




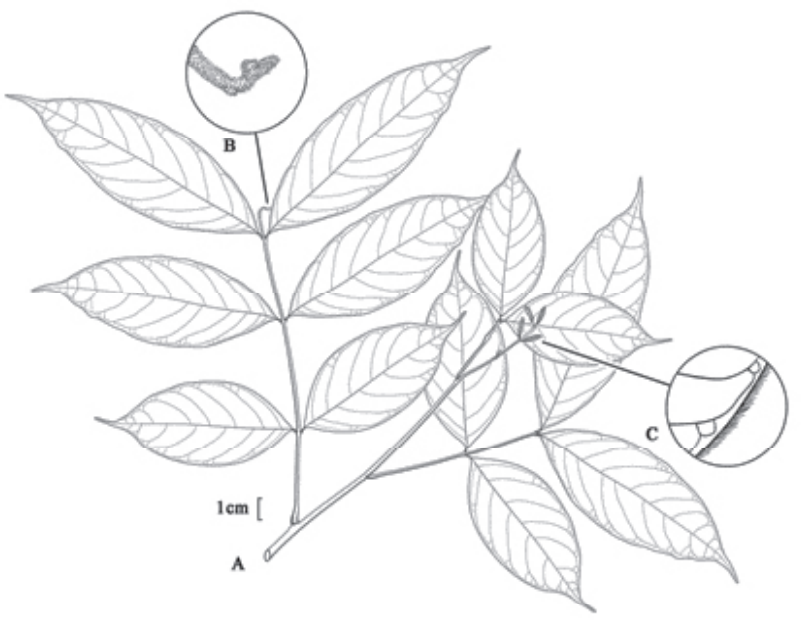

Fig. 3. Guarea ciliata Al. Rodr. (A. Rodríguez 8400, INB).
A. Hábito.
B. Yema terminal de la hoja.
C. Margen ciliado del foliolo.
D. Flor masculina.
E. Corte longitudinal de flor masculina.
F. Pétalo de flor masculina.
G. Antera.
H. Fruto.
I. Corte longitudinal de fruto.
J. Corte transversal de fruto.
K. Fruto.

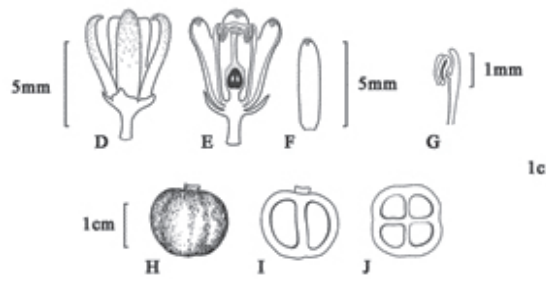

Fig. 4. Guarea constricta Al. Rodr. (A. Estrada 2016, INB).
A. Hábito.
B. Inflorescencia femenina.
C. Yema terminal de la hoja.
D. Pétalo de flor femenina.
E. Ovario de flor femenina.
F. Anteroide adherido al tubo estaminal.
G. Corte transversal de ovario de flor femenina.
H. Flor femenina.
I. Corte longitudinal de flor femenina.
J. Fruto.

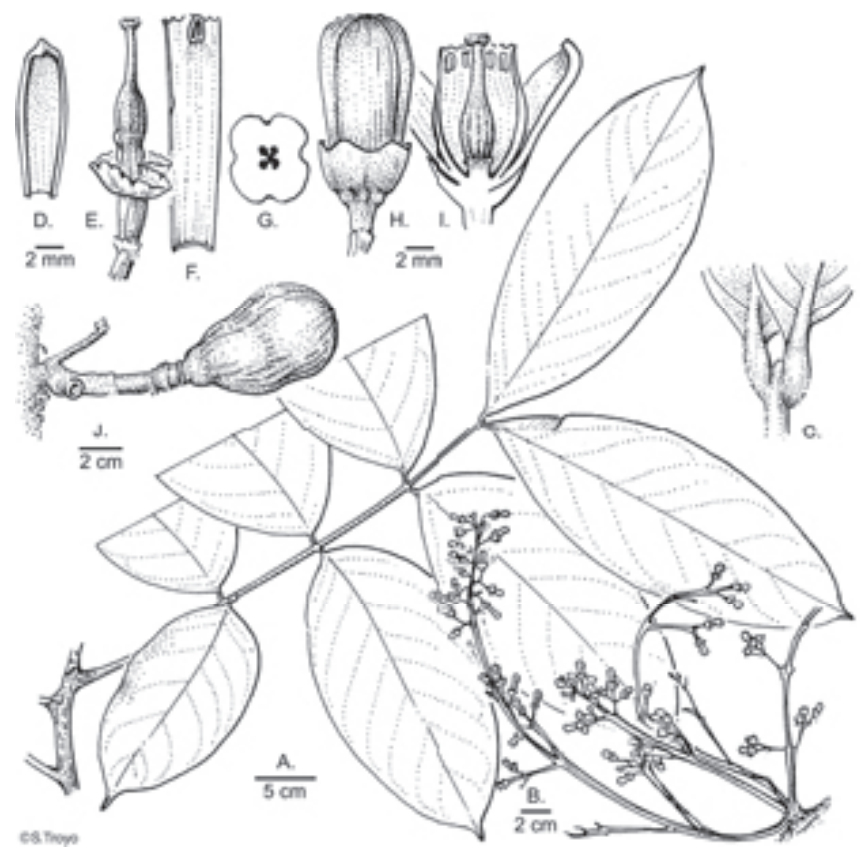


Fig. 5. Guarea corticosa Al. Rodr. (R. Aguilar 488, INB).
A. Hábito.
B. Corteza suberizada.
C. Yema terminal de la hoja.
D. Botón de flor femenina.
E. Corte longitudinal de botón de flor femenina.
F. Pétalo de flor femenina.
G. Corte transversal de ovario de flor femenina.
H. Anteroide.
I. Inflorescencia femenina.
J. Corte transversal de fruto.
K. Corte longitudinal de fruto.
L. Fruto.
M. Antera.
N. Botón de flor masculina.
N. Corte longitudinal de botón de flor masculina.
O. Pétalo de flor masculina.
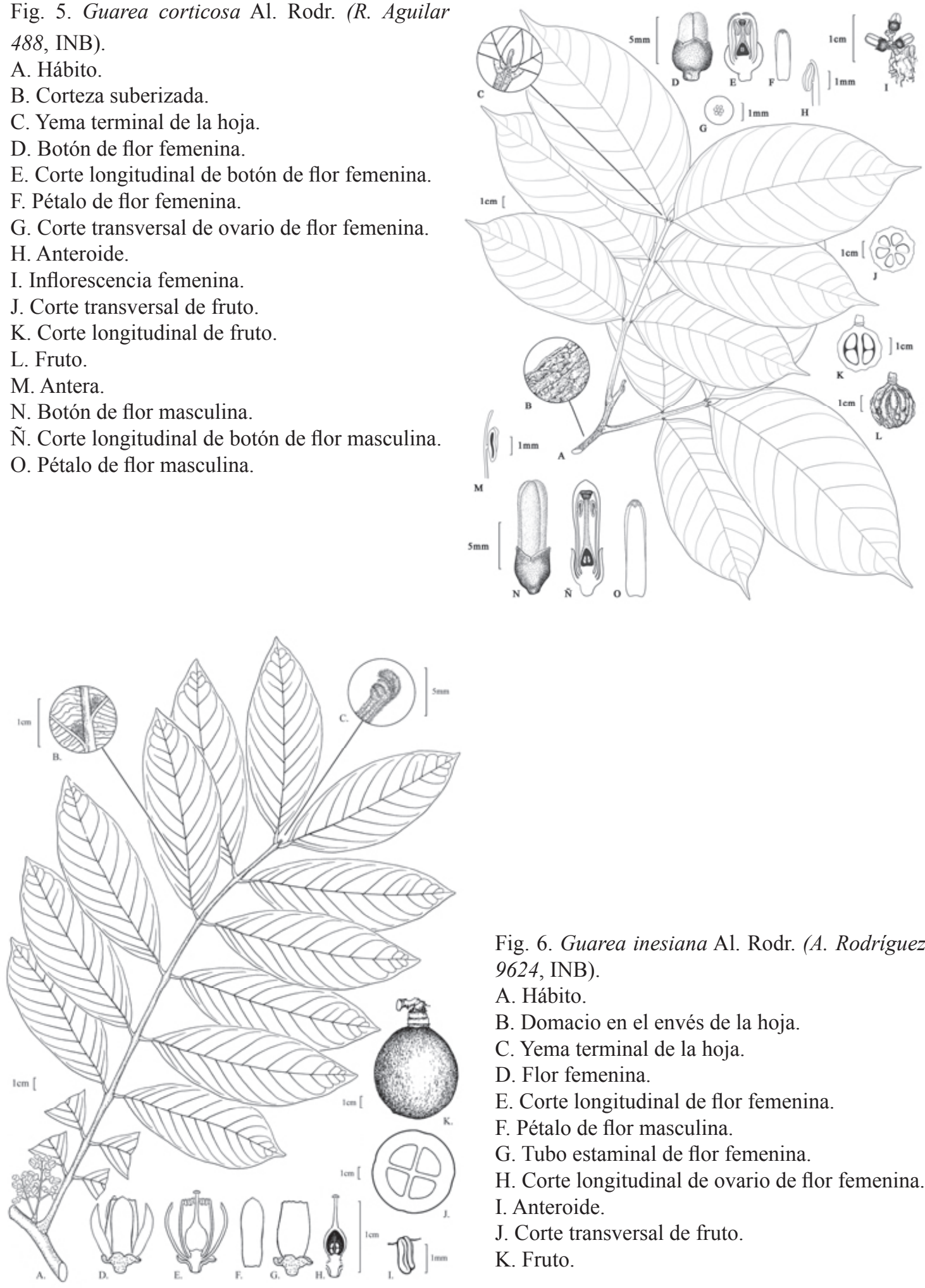

Fig. 6. Guarea inesiana Al. Rodr. (A. Rodríguez 9624, INB).
A. Hábito.
B. Domacio en el envés de la hoja.
C. Yema terminal de la hoja.
D. Flor femenina.
E. Corte longitudinal de flor femenina.
F. Pétalo de flor masculina.
G. Tubo estaminal de flor femenina.
H. Corte longitudinal de ovario de flor femenina.
I. Anteroide.
J. Corte transversal de fruto.
K. Fruto. 


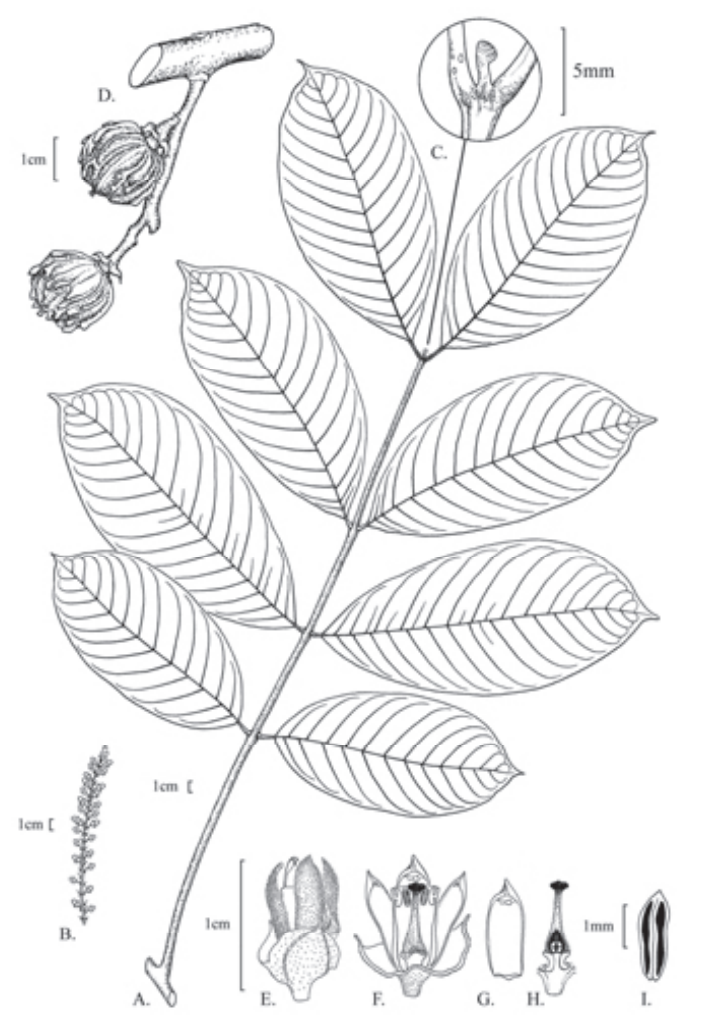

Fig. 8. Guarea montana Al. Rodr. (Z. Fuentes 653, INB).
A. Hábito.
B. Yema terminal de la hoja.
C. Peciólulo.
D. Flor masculina.
E. Corte longitudinal de flor masculina.
F. Pétalo de flor masculina.
G. Corte longitudinal de ovario de flor masculina.
H. Antera.
I. Flor femenina.
J. Corte longitudinal de flor femenina.
K. Pétalo de flor femenina.
L. Corte longitudinal de ovario de flor femenina.
M. Anteroide.
N. Fruto.
Ñ. Corte longitudinal de fruto.
O. Corte transversal de fruto.

Fig. 7. Guarea macrocalyx Al. Rodr. (A. Estrada 832, INB).
A. Hábito.
B. Inflorescencia masculina.
C. Yema terminal de la hoja.
D. Frutos.
E. Flor masculina.
F. Corte longitudinal de flor masculina.
G. Pétalo de flor masculina.
H. Corte longitudinal de ovario de flor masculina. I. Antera.

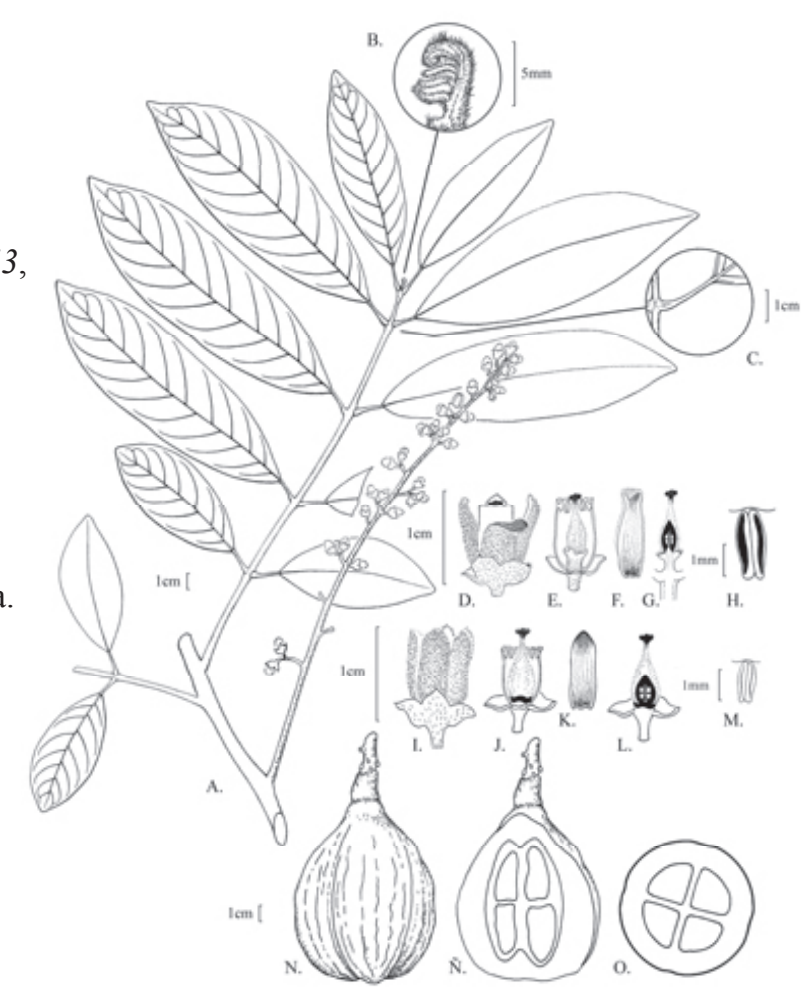




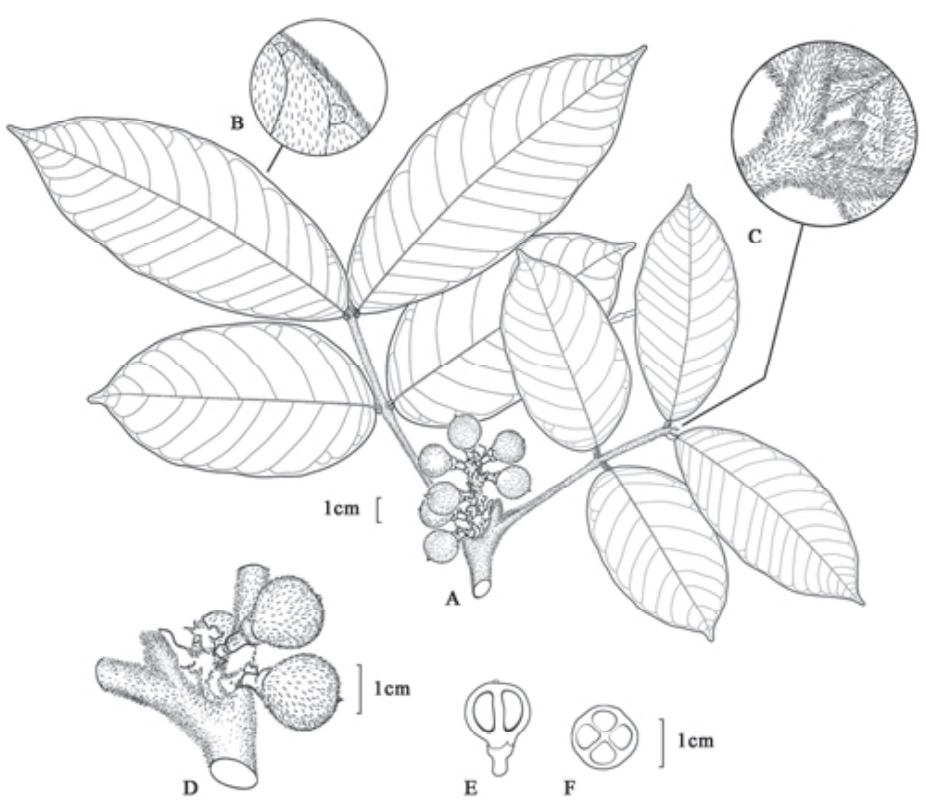

Fig. 9. Guarea pilosa Al. Rodr. (G. Rivera 1098, INB).

A. Hábito.

B. Margen ciliado de la hoja.

C. Yema terminal de la hoja.

D. Infrutescencia.

E. Corte longitudinal de fruto.

F. Corte transversal de fruto.

Fig. 10. Guarea tafae-malekui Al. Rodr. (A. Rodríguez 6238, INB).
A. Hábito.
B. Yema terminal de la hoja.
C. Flor masculina.
D. Corte longitudinal de flor masculina.
E. Pétalo de flor masculina.
F. Corte longitudinal de ovario de flor masculina.
G. Antera.
H. Botón de flor masculina.
I. Fruto.
J. Corte longitudinal de fruto.
$\mathrm{K}$. Corte transversal de fruto.

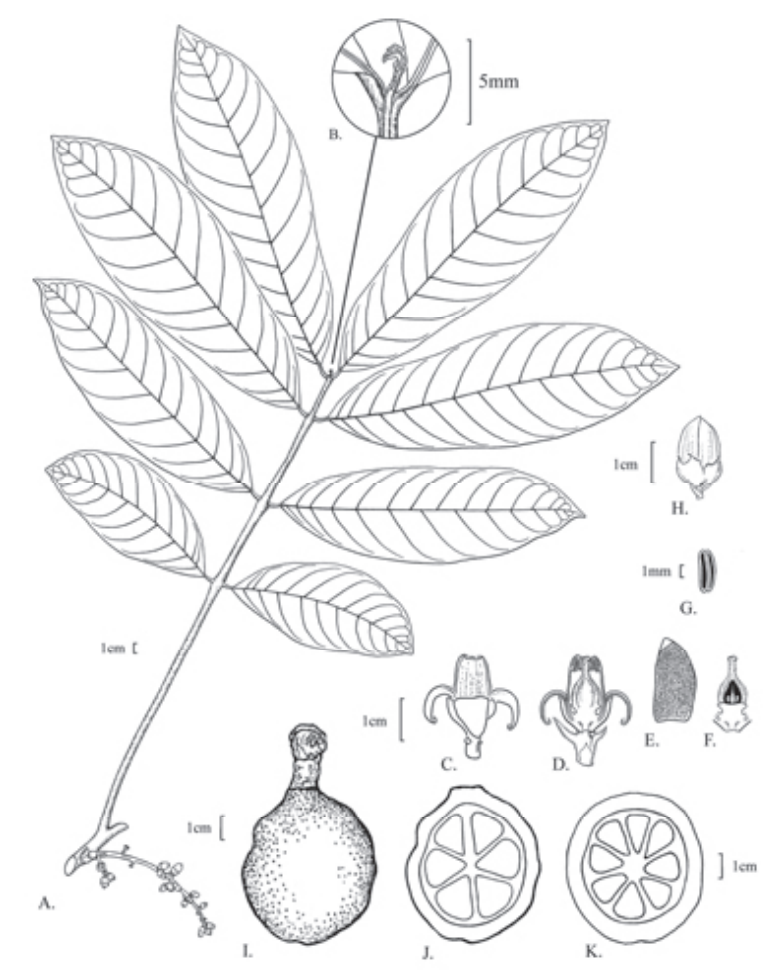

